UNIVERSIDADE DE SÃO PAULO

FACULDADE DE CIÊNCIAS FARMACÊUTICAS

Departamento de Análises Clínicas e Toxicológicas

Programa de Pós-Graduação em Farmácia

Área Fisiopatologia

\title{
Mapeamento de hotspots de transmissão de malária utilizando geolocalização de pacientes
}

\author{
Lucas Esteves Cardozo
}

Dissertação para obtenção do Título de Mestre

Orientador: Prof. Dr. Helder Takashi Imoto Nakaya

São Paulo

2018 
UNIVERSIDADE DE SÃO PAULO

FACULDADE DE CIÊNCIAS FARMACÊUTICAS

Departamento de Análises Clínicas e Toxicológicas

Programa de Pós-Graduação em Farmácia

Área Fisiopatologia

\title{
Mapeamento de hotspots de transmissão de malária utilizando geolocalização de pacientes
}

\author{
Lucas Esteves Cardozo \\ Versão corrigida da Dissertação conforme resolução CoPGr 6018. \\ Original encontra-se disponível no Serviço de Pós-Graduação da FCF/USP \\ Dissertação para obtenção do Título de Mestre \\ Orientador: Prof. Dr. Helder Takashi Imoto Nakaya
}

São Paulo

2018 
Autorizo a reprodução e divulgação total ou parcial deste trabalho, por qualquer meio convencional ou eletronico, para fins de estudo e pesquisa, desde que citada a fonte.

Ficha Catalográfica elaborada eletronicamente pelo autor, utilizando o programa desenvolvido pela Seção Técnica de Informática do ICMC/USP e adaptado para a Divisão de Biblioteca e Documentação do Conjunto das Químicas da USP

Bibliotecária responsável pela orientação de catalogação da publicação: Marlene Aparecida Vieira - CRB - 8/5562

Cardozo, Lucas Esteves

Mapeamento de hotspots de transmissão de malária utilizando geolocalização de pacientes / Lucas Esteves Cardozo. - São Paulo, 2018. $63 \mathrm{p}$.

Dissertação (mestrado) - Instituto de Química da Universidade de São Paulo. Departamento de Química Fundamental. Orientador: Nakaya, Helder Takashi Imoto

1. Mosquitos. 2. Malária. 3. Geolocalização. I T. II. Nakaya, Helder Takashi Imoto, orientador. 
Dedico este trabalho à minha família;

à minha companheira, Ingrid; aos meus queridos amigos. 



\section{Agradecimentos}

Agradeço a minha família pois, sem eles, nada disso seria possível. Minha mãe, por sempre se preocupar com a minha sanidade mental e física e, meu pai, por ter providenciado todo o suporte necessário durante esse período. Fernanda que, através de discussões científicas e políticas me ajudou a ver o mundo de uma forma diferente e, Camila, por sempre desafiar a minha mente com conhecimentos esquecidos do ensino médio. O irmão canino mais novo, Johnny também merece os agradecimentos, por escutar minhas reclamações em troca de carinho e comida.

Agradeço também a minha querida companheira, Ingrid, por ter estado ao meu lado nos momentos mais difíceis da minha formação. Por se preocupar comigo durante os expedientes de 15 horas no laboratório; por, sempre que possível, me acompanhar durante as refeições românticas no bandejão; por sempre apoiar as minhas ideias mais malucas. Em resumo, por ser compreensiva e acreditar em mim.

Agradeço a todos os amigos do CSBL que sempre fizeram da vivência no laboratório uma experiência incrível. Agradeço por todos aqueles bate-papos durante o café, pelas discussões políticas e científicas do pós-almoço, pelos journal clubs, pelas partidas no FIFA e pelas risadas. Especificamente para este trabalho, agradeço à mentoria matemática do Gustavo, computacional do Matheus, e filosófico-científica do Diógenes, Thiago, César e Tiago.

Agradeço aos queridos amigos do Pico da Flor Roxo, em especial à Sadia, por sempre confiar em mim e dar todo o suporte possível nos momentos difíceis. 
Agradecimento especial às pessoas em Manaus que de fato fizeram esse projeto sair do papel. Ao Vanderson Sampaio pelo suporte logístico e científico ao projeto. À Sara Maia por ter feito um ótimo trabalho na coleta de dados dos pacientes. Ao Prof. Dr. Wuelton Monteiro e ao Prof. Dr. Marcus Lacerda, que fizeram possível o estabelecimento da FMT-HVD como principal centro de coleta para este trabalho.

Agradeço aos professores Marcelo Urbano, Tamara Nunes Camara e Eduardo Lani pelos elogios e pelas discussões construtivas no período de qualificação.

Agradeço ao Conselho Nacional de Desenvolvimento Científico e Tecnológico (CNPq), à CAPES e à Bill and Melinda Gates Foundation pelo suporte financeiro à este projeto.

Por último, um agradecimento especial ao meu orientador, Helder Nakaya. Por ter investido seu tempo na minha formação desde a graduação. Por ter acreditado no meu potencial. Pelos seus insights científicos geniais. Por ter me ensinado sobre as nuances do mundo acadêmico atual. Por saber reconhecer os momentos de crítica e de elogio. E, por último, mas não menos importante, por todos os churrascos de final de ano, pizzas noturnas no laboratório e pelas rodadas de cerveja. 



\section{Resumo}

CARDOZO, L. E. Mapeamento de hotspots de transmissão de malária utilizando geolocalização de pacientes. 2018. Dissertação (Mestrado) - Faculdade de Ciências Farmacêuticas, Universidade de São Paulo, São Paulo, 2018.

A identificação de focos de transmissão pode ser de grande utilidade no controle da malária. Por esse motivo, hospitais em regiões endêmicas buscam saber os locais que foram visitados anteriormente por pacientes. No entanto, tais informações, obtidas através de questionários fornecidos aos pacientes, são geralmente vagas e muitas vezes imprecisas. Isto torna o processo manual, lento e de pouca valia em estudos epidemiológicos de larga escala. Baseando-se no fato de que uma parcela significativa da população possui celulares com GPS, o objetivo deste projeto é melhorar a acurácia, organização e dinâmica do processo de coleta de dados de geolocalização de pacientes infectados. Um sistema (https://sipos.fcf.usp.br) foi desenvolvido para que pacientes que chegam aos hospitais possam, sob consentimento voluntário, fornecer os dados de GPS dos seus celulares. Os dados dos usuários, que são tratados de forma anônima, são automaticamente processados e armazenados de forma segura. Através do sistema SiPoS Explorer, epidemiologistas e especialistas em saúde pública podem explorar e analisar os dados de geolocalização, permitindo, desta forma, que regiões vulneráveis sejam priorizadas durante campanhas de controle.

Palavras-chave: Mosquito. Malária. Geolocalização. 



\begin{abstract}
CARDOZO, L. E. Mapping hotspots of malaria transmission using patients geolocation data. 2018. Dissertação (Mestrado) - Faculdade de Ciências Farmacêuticas, Universidade de São Paulo, São Paulo, 2018.

The identification of regions with high rates of infection can be of great use in the control of malaria. For this reason, hospitals in endemic regions seek to know the places previously visited by patients. However, such information, obtained through questionnaires provided to patients, is usually vague, inaccurate and not integrated into databases. This makes the process manual, slow and of little value in large-scale epidemiological studies. Based on the fact that a significant portion of the population has smartphones equipped with GPS, this project aims to improve the accuracy and organization of the process of collecting geolocation data from infected patients. The Sickness Positioning System (https://sipos.fcf.usp.br) was developed so that patients who arrive at hospitals can, with voluntary consent, provide the GPS data collected by their smartphones. User data, which is handled anonymously, is automatically processed and securely stored. Through the SiPoS Explorer system (https://sipos.fcf.usp.br/explorer), epidemiologists and public health experts can explore and analyze geolocation data, thereby allowing vulnerable regions to be prioritized during control campaigns.
\end{abstract}

Keywords: Mosquito. Malaria. Geolocation. 



\section{Sumário}

$\begin{array}{ll}\text { 1. Introdução } & 13\end{array}$

2. Objetivos 17

2.1. Objetivo principal 17

2.2. Objetivos específicos 17

3. Métodos 18

3.2. Coleta dos dados 18

3.3. Comitê de Ética 19

3.4. Sistema SiPoS 20

3.4.1 Infraestrutura Computacional na Nuvem 20

3.4.1.1 Provisionamento 20

3.4.1.2 Configuração $\quad 22$

3.4.2 Arquitetura do sistema 23

3.4.2.1 Aplicação de coleta $\quad 24$

3.4.2.2 Aplicação de processamento dos dados 26

3.4.2.3 Aplicação de exploração 26

3.5. Processamento e análise dos dados de localização 27

$\begin{array}{ll}3.5 .1 \text { Formato dos Dados } & 27\end{array}$

3.5.2 Filtro e segmentação temporal 28

3.5.2 Detecção de potenciais hotspots $\quad 29$

3.5.2.1 Detecção de pontos de parada 30

$\begin{array}{ll}\text { 3.5.2.3 Estimação da densidade kernel (KDE) } & 31\end{array}$

3.5.2.3 Análise de agrupamento (clustering) 32

4. Resultados e Discussão 35

4.1. Sickness Positioning System (SiPoS) 35

$\begin{array}{ll}\text { 4.3. Malária em Manaus } & 37\end{array}$

4.4. Aplicações alternativas 43

4.5. Limitações $\quad 45$

5. Conclusão 45

$\begin{array}{ll}\text { Referências Bibliográficas } & 46\end{array}$

Anexos $\quad 49$ 


\section{Introdução}

De acordo com dados do World Malaria Report, em 2016, aproximadamente metade da população mundial vivia em áreas de risco de transmissão do agente causador da malária. Com uma estimativa de 216 milhões de casos em 2016, a malária se distribui de maneira não uniforme pelos continentes, com aproximadamente $90 \%$ dos casos estimados para o continente africano, $\sim 7 \%$ dos casos no sudeste asiático e $\sim 0.5 \%$ dos casos no continente americano (TDR/WHO, 2017). Apenas no Brasil, foram estimados, para este mesmo ano, um total de 157 mil casos. Estas estimativas colocam a malária no topo da lista de doenças infecciosas que causam mais problemas de saúde pública no mundo.

Considerando a dimensão do impacto causado por essa doença, diferentes estratégias de controle já foram propostas e aplicadas. Causada por protozoários do gênero Plasmodium, que são transmitidos para os humanos através da picada de mosquitos do gênero Anopheles, a malária expõe duas principais interfaces a serem exploradas pelas medidas de controle: estratégias que focam na redução do pool de parasitas - através do tratamento dos pacientes infectados - e estratégias que buscam limitar o contato dos vetores com os humanos.

Dentre as estratégias mais utilizadas para redução do pool de parasitas está o tratamento dos pacientes com terapias que consistem na administração de medicamentos como cloroquina, primaquina e artemisinina, variando de acordo com a espécie causadora, fase do ciclo de vida em que se encontram os parasitas, gravidade 
do quadro, entre outros (ABAY, 2013; COMMONS et al., 2018). Por sua vez, a aplicação de inseticidas associados ou não ao uso de redes de proteção (ALONSO et al., 1991; NTONIFOR; VEYUFAMBOM, 2016), buscam, seja através da redução da população de vetores ou através do uso de barreiras físicas, reduzir a interface de contato entre os mosquitos e a população humana, nas áreas de risco.

A vigilância epidemiológica é de grande importância para que as técnicas citadas acima sejam planejadas e executadas de maneira mais efetiva pelas diferentes esferas da gestão pública. No Brasil, a malária é uma doença de notificação compulsória, ou seja, todos os casos suspeitos e confirmados devem ser notificados ao Ministério da Saúde (OLIVEIRA-FERREIRA et al., 2010). O protocolo de notificação envolve o preenchimento de uma ficha de notificação de caso, que alimenta o Sistema de Informação de Vigilância Epidemiológica (SIVEP) de malária. Nesta ficha, informações como local provável de infecção e algumas variáveis clínicas qualitativas, são coletadas. Esses dados são então compilados e utilizados pelas Secretarias de Saúde para definir as políticas de controle epidemiológico.

A informação a respeito do local provável de infecção coletada no protocolo de notificação, porém, é subjetiva, dependendo da recordação do paciente e podendo ser influenciada pelo vieses sociais. Dessa forma, a incerteza por trás da real acurácia deste dado se torna uma limitação. Para superar esta limitação e, consequentemente, gerar políticas de controle mais eficazes, o uso de fontes de dados de localização mais precisas se mostra necessário.

Diversos estudos reconhecem que a propagação da malária (PROTHERO, 1977; 
WESOLOWSKI et al., 2012) e de outras doenças infecciosas (CUMMINGS et al., 2004; GOG et al., 2014; GRENFELL; BJØRNSTAD; KAPPEY, 2001) está diretamente associada aos padrões de mobilidade e deslocamento humano, e que, negligenciar a mobilidade humana como um fator relevante no desenvolvimento das medidas de controle pode ameaçar a eliminação da doença nas regiões endêmicas. Seguindo, portanto, a tendência de incluir este fator no contexto epidemiológico, alguns estudos propuseram o uso de GPS data loggers para a coleta de dados de geolocalização (SEARLE et al., 2017; VAZQUEZ-PROKOPEC et al., 2009, 2013). Utilizando esta fonte de dados, os autores foram capazes de elicitar, em uma pequena escala geográfica, padrões sazonais e não-sazonais de deslocamento humano que podem exercer impactos na dinâmica epidemiológica das doenças em questão.

Estudos como os citados acima trouxeram avanços relevantes na compreensão da distribuição espacial, dinâmica das doenças e, consequentemente, na definição de políticas mais efetivas para o controle epidemiológico. No entanto, a aplicação de suas técnicas na escala pública se torna difícil, dado que os meios de obtenção dos dados de localização nestes estudos envolvem grande mobilização de recursos humanos, tecnológicos e financeiros. Deste modo, uma possível alternativa para superar algumas dessas desvantagens são os smartphones.

O uso de smartphones, que são hoje equipados, em sua maioria, com tecnologias de geolocalização, representa uma fonte rica e barata para obtenção de dados desta natureza. De acordo com dados da Nielsen-IBOPE (http://goo.gl/VzrXsd), o número de pessoas que utilizam smartphones para acessar a internet no Brasil 
chegou a 72,4 milhões em 2015, por exemplo. A quantidade de aparelhos em uso não é a única vantagem na coleta dos dados. Com o aumento no número de smartphones, ocorreu uma evolução nas tecnologias de localização geográfica a eles incorporadas. O uso de GPS associado a redes telefônicas (MA, 2003) e ao sistema de posicionamento Wi-Fi (VAUPEL et al., 2010), elevou a quantidade e acurácia de dados obtidos, sendo assim, uma boa ferramenta para a coleta de dados geográficos.

Estudos recentes utilizaram dados de telefonia para fins epidemiológicos. (BUCKEE et al., 2013; LE MENACH et al., 2011; WESOLOWSKI et al., 2012, 2015). Estes estudos se baseiam, primariamente, num registro chamado Call Detail Record. Tal registro é armazenado pelas empresas provedoras de telefonia à cada ligação realizada ou mensagem enviada, contendo um identificador único do chip utilizado na chamada, um identificador da torre utilizada para estabelecer conexão e um valor temporal associado a esse evento. A partir deste dado, é possível aproximar a localização do usuário no momento da chamada. Dados de CDR foram utilizados nestes estudos para avaliar padrões de mobilidade e construir modelos de importação de parasitas entre diferentes regiões. A acurácia das localizações obtida pelos dados de $C D R$, no entanto, varia de acordo com a densidade das torres de telefonia disponíveis no local (WILLIAMS et al., 2015).

A fim de munir os epidemiologistas de dados mais acurados e, consequentemente, colaborar com a criação de medidas de controles mais eficazes, propomos, neste presente trabalho, a criação de um sistema para coleta, análise e exploração de dados de GPS dos smartphones de pacientes com malária. 


\section{Objetivos}

\subsection{Objetivo principal}

Utilizar dados do histórico de localização geográfica dos pacientes com malária para buscar por regiões de hotspots de transmissão do agente etiológico da doença.

\subsection{Objetivos específicos}

- Desenvolvimento da aplicação web para coleta dos dados de geolocalização dos pacientes diagnosticados com malária no hospital;

- Implementação computacional do pipeline de processamento e análise dos dados de geolocalização coletados;

- Desenvolvimento da aplicação web para exploração visual, por parte dos epidemiologistas e agentes de saúde, das análises realizadas.

\section{Métodos}

\subsection{Coleta dos dados}

A forma mais eficiente para obter dados de geolocalização coletados por dispositivos móveis se dá através da instalação de um aplicativo de coleta nos 
smartphones dos pacientes. No entanto, o aplicativo móvel só teria acesso aos dados de localização coletados a partir da data de sua instalação, o que tornaria inviável a análise retrospectiva, visto que o paciente instalaria o aplicativo num momento posterior à suposta data de infecção. Desta forma, uma alternativa para a obtenção do histórico de localização é o Google Takeout ${ }^{\circledR}$. Este serviço, que pode ser encontrado em https://www.google.com/settings/takeout, permite que seus usuários façam download de diversas informações pessoais armazenadas em servidores do Google®. O histórico de localização geográfica é uma das informações que podem ser obtidas através deste serviço. Estes dados são confidenciais e podem ser apenas acessados e disponibilizados pelos próprios usuários.

A fim de centralizar o recebimento dos dados dos pacientes um aplicativo web, denominado "SiPoS - Sickness Positioning System", foi desenvolvido. Este aplicativo foi acessado pelos pacientes no hospital, sob orientação dos colaboradores. O website cumpre o papel de informar o paciente a respeito da destinação e do uso dos dados por ele doados, além de guiá-lo para o download através da plataforma Google Takeout ${ }^{\circledR}$ e para o envio dos dados através do próprio website. Além disso, a ferramenta implementa um mecanismo que impede o envio dos dados sem a aceitação do termo de consentimento (anexo A). 0 envio dados é realizado de forma anônima.

O procedimento de coleta de dados no hospital da Fundação de Medicina Tropical Doutor Heitor Vieira Dourado (FMT-HVD) foi idealizado e executado pela mestranda Sara Maia, sob orientação do Dr. Vanderson Sampaio, da Fundação de 
Vigilância em Saúde do estado do Amazonas e com apoio científico e logístico dos professores Dr. Wuelton Monteiro e Dr. Marcus Lacerda, ambos da FMT-HVD.

\subsection{Comitê de Ética}

O uso de informações confidenciais, como o histórico de localização dos pacientes, levanta questões de cunho ético para a pesquisa (ONLINE; MCNAMEE, 2005). Para que pudéssemos dar início à coleta de dados, o projeto foi submetido à Plataforma Brasil e aprovado (CAAE: 68428917.0.0000.0005) pelo Comitê de Ética da Fundação de Medicina Tropical Doutor Heitor Vieira Dourado.

\subsection{Sistema SiPoS}

Por se tratar de um estudo potencialmente multicêntrico, envolvendo diversos centros de coleta, a ferramenta web foi desenvolvida visando a alta disponibilidade i.e. capacidade de servir usuários a todos os momentos - e escalabilidade - i.e capacidade de atender a demanda flexível de usuários. Desta forma, em períodos do ano em que há um aumento na quantidade de pacientes exibindo sintomas decorrentes de flutuações normais relacionadas a fatores ambientais sazonais (BARROS; HONÓRIO, 2007; BHATT et al., 2013; COSTA; CALADO, 2016) - o sistema não perderá disponibilidade e permanecerá recebendo dados. 


\subsubsection{Infraestrutura Computacional na Nuvem}

Para garantir a alta disponibilidade e escalabilidade do website, diferentes ferramentas foram utilizadas em conjunto para criar e configurar um sistema de máquinas virtuais na nuvem.

\subsubsection{Provisionamento}

Seguindo os princípios da "Infraestrutura como Código" (MORRIS, 2016), Terraform (https://www.terraform.io/) (fig. 1) foi utilizado para automatizar o provisionamento de múltiplas máquinas. Esta ferramenta possui a vantagem de utilizar uma forma declarativa - através de arquivos de configuração escritos na sintaxe Hashicorp Configuration Language $(\mathrm{HCL})$ - para obtenção recursos computacionais em diferentes provedores na nuvem. Um exemplo de sua notação pode ser observado na figura 2.

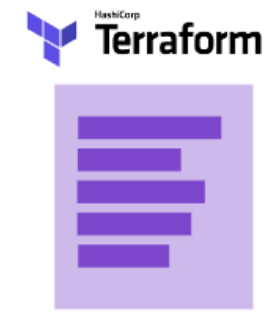

Arquivo de configuração
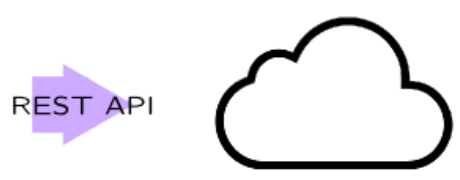

Provedor na Nuvem

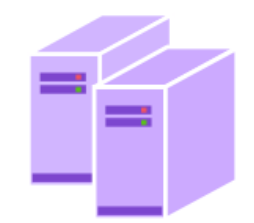

Infraestrutura na Nuvem

Figura 1. Criação da infraestrutura computacional na nuvem utilizando Terraform. O programa de linha de comando estabelece uma interface programática com diversos provedores na nuvem através de suas REST APIs para criação de recursos computacionais na nuvem. 


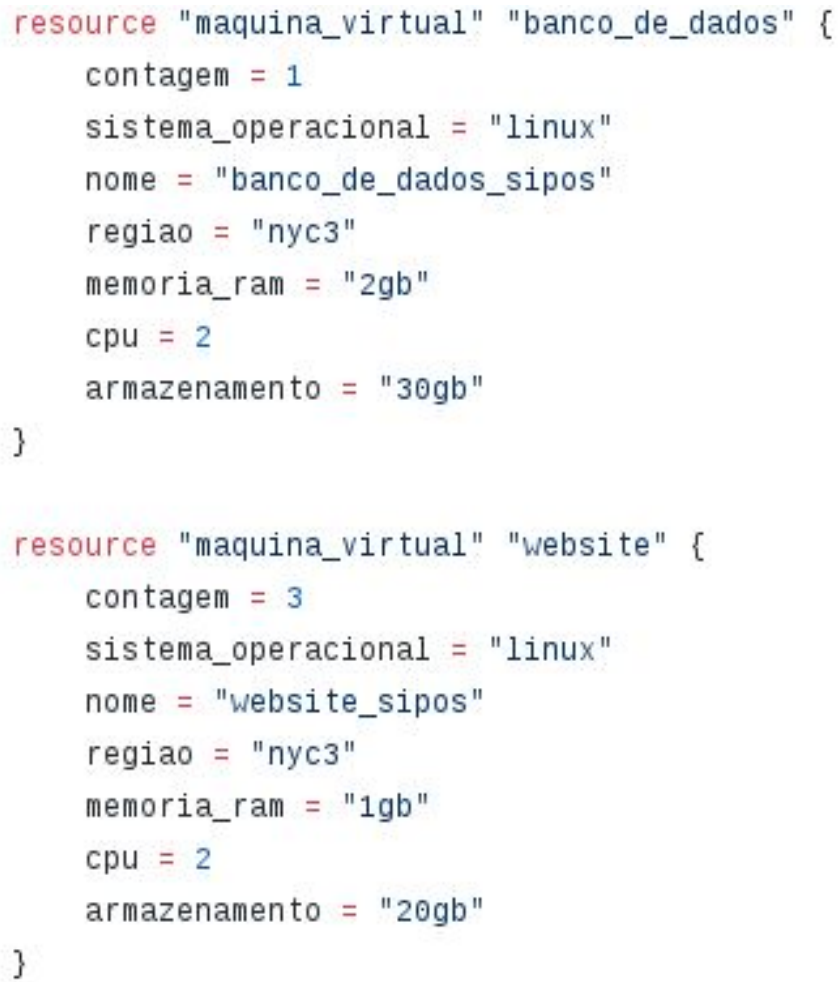

Figura 2. Exemplo ilustrativo do formato declarativo utilizado pelo Terraform para provisionamento de máquinas na nuvem. A criação dos recursos computacionais na nuvem se dá através da diretiva "resource" neste arquivo de configuração.

\subsubsection{Configuração}

Após a criação das máquinas, todo um processo de configuração e instalação de dependências é necessário para que a aplicação seja finalmente executada. Para tal, a ferramenta Ansible (https://www.ansible.com/) foi utilizada. Da mesma forma que o Terraform, esta ferramenta - também de código aberto - implementa uma forma declarativa para a configuração das máquinas previamente provisionadas. Desta forma, em seu arquivo de configuração no formato YAML são definidas tarefas que serão aplicadas à todas ou a apenas um subgrupo das máquinas (fig. 3). 


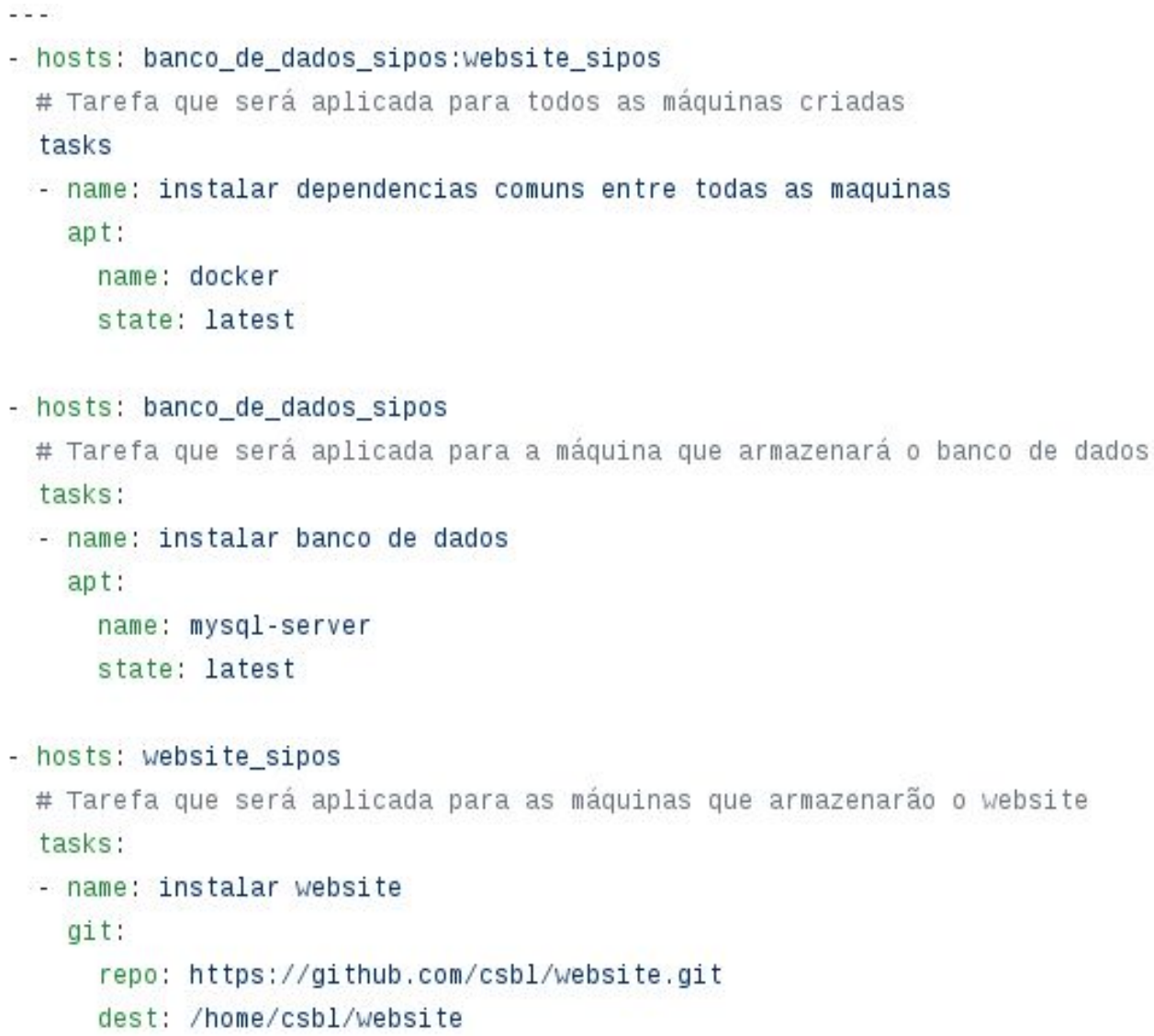

Figura 3. Exemplo ilustrativo do formato declarativo utilizado pelo Ansible para configuração remota das máquinas na nuvem. A diretiva "hosts" indica para quais máquinas devem ser aplicadas as configurações que são descritas abaixo da diretiva "tasks". Na figura, a primeira configuração é aplicada para todas as máquinas, a segunda é aplicada apenas à máquina que armazenará o banco de dados e a terceira é aplicada apenas para as máquinas que armazenam o website

\subsubsection{Arquitetura do sistema}

O sistema desenvolvido neste trabalho é composto de 3 elementos principais: a aplicação de coleta dos dados ( https://sipos.fcf.usp.br ), aplicação de processamento dos dados e, por último, a aplicação de exploração ( https://sipos.fcf.usp.br/explorer) e análise dos dados. A estrutura do sistema e o fluxo de dados entre os elementos do sistema podem ser observado na figura 4. 


\section{Coleta}

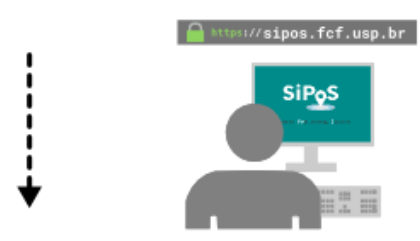

Processamento

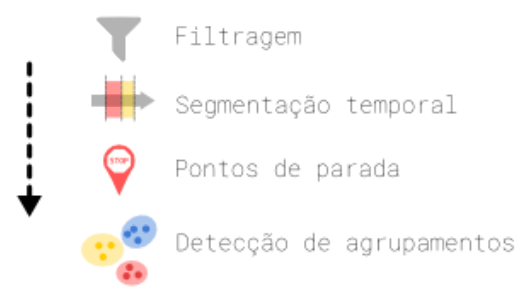

\section{Armazenamento}

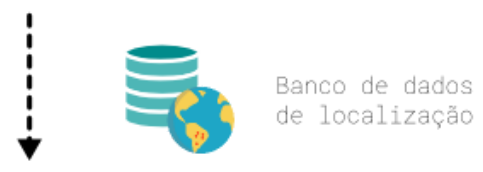

Exploração

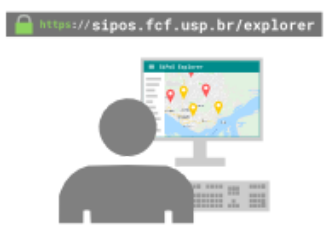

Figura 4. Fluxo de dados e arquitetura do sistema. O paciente acessa o website (sipos.fcf.usp.br) através de seu navegador. Os dados enviados pelo paciente são filtrados, segmentados e analisados de diferentes formas, dependendo da doença em questão. Os dados processados, por sua vez são armazenados num banco de dados que é acessado pelos epidemiologistas responsáveis pela exploração dos dados, através de outra aplicação web, SiPoS Explorer (sipos.fcf.usp.br/explorer).

\subsubsection{Aplicação de coleta}

O desenvolvimento de aplicações web pode ser dividido em duas camadas: front-end, camada responsável por lidar com a interface com usuário que é exibida no 
navegador; back-end, camada responsável pela lógica da aplicação, que permanece em execução no cluster de máquinas.

Considerando um público alvo heterogêneo, que inclui pessoas de diversas idades e backgrounds, a interface com os usuários deverá ser intuitiva e informativa, revelando todas as informações que podem ser úteis. Além da simplicidade a interface também deverá apresentar um design responsivo, onde os elementos da página se ajustam às diferentes dimensões da tela. Dessa forma o site permite uma boa interação com usuários acessando tanto de computadores como também de smartphones e tablets.

As tecnologias que utilizadas para o desenvolvimento da interface gráfica foram: HyperText Markup Language (HTML), linguagem interpretada pelo navegador e utilizada para definir elementos na página; Cascade Style Sheets (CSS), também interpretada pelo navegador, é responsável por definir o estilo dos elementos descritos no HTML, como cor e tamanho; JavaScript, linguagem utilizada pelo navegador para lidar com a lógica da interface gráfica e para estabelecer comunicação com o back-end da aplicação.

O back-end, camada responsável por lidar com as requisições dos usuários e salvar os dados enviados no banco de dados, foi desenvolvido utilizando o framework Flask, para linguagem Python de programação.

Por questões de segurança, o servidor web foi configurado para se comunicar com o cliente apenas através do protocolo HTTPS, que permite que todos os dados enviados pelo usuário para o servidor, e vice-versa, sejam criptografados. 


\subsubsection{Aplicação de processamento dos dados}

Os dados obtidos pela aplicação de coleta são processados paralelamente através do sistema de gerenciamento de tarefas assíncronas para Python, Celery. Os dados de cada paciente são colocados numa fila ordenada de tarefas e são processados em background. O pipeline de processamento consiste de duas etapas. A etapa inicial é a de pré-processamento dos dados, composta pela filtragem e segmentação temporal (de acordo com a doença em questão). A segunda etapa consiste na busca pelos pontos de parada nas trajetórias e na análise de agrupamento das trajetórias. Finalmente, os dados processados são armazenados no banco de dados e serão consumidos pela aplicação de exploração. Mais informações sobre a motivação por trás de cada um dos passos envolvidos no processamento podem ser encontradas na seção 3.5 .

\subsubsection{Aplicação de exploração}

Para que os dados coletados e processados possam ser explorados e interpretados pelos especialistas, a ferramenta SiPoS Explorer foi desenvolvida. Criada utilizando o framework javascript Vue.js, a aplicação expõe, em um mapa interativo, o resultado da coleta e processamento dos dados. O usuário (epidemiologista) disporá de diversas opções de filtragem dos dados a serem visualizados. Dentre as opções, é possível: escolher quais pacientes (através do identificador) deseja-se visualizar os 
dados; filtrar por um intervalo de tempo absoluto, por exemplo "entre o dia 01/01/2017 e 01/03/2018", permitindo a observação por padrões em épocas específicas do ano; filtrar por um intervalo de tempo relativo ao momento em que o paciente foi diagnosticado no hospital, por exemplo "de 3 a 10 dias antes do diagnóstico", permitindo que se avalie padrões espaciais em períodos específicos da evolução da doença; por último, o usuário ainda pode escolher observar os pontos classificados como ponto de parada (onde o paciente ficou parada por um determinado período) ou ponto de movimento (onde o paciente estava se deslocando). No caso dos epidemiologistas interessados em analisar os dados de pacientes diagnosticados malária, os dados do Sistema de Vigilância Epidemiológica de Malária (SIVEP) também estão incluídos e podem ser filtrados e comparados com as regiões reportadas pelo processamento e análise do SiPoS.

\subsection{Processamento e análise dos dados de localização}

\subsubsection{Formato dos Dados}

Os dados enviados pelos pacientes se encontram no formato JavaScript

Object Notation (JSON). A estrutura deste arquivo consiste em uma lista chamada "locations", que armazena as coordenadas geográficas (latitudeE7, longitudeE7), a data e hora (timestampMs) da coleta, um valor de exatidão associado à coordenada (accuracy), em altitude e uma lista de possíveis atividades que estavam sendo realizadas pelo paciente naquele momento, associadas à um valor de confiança 
(activity) (fig. 5).

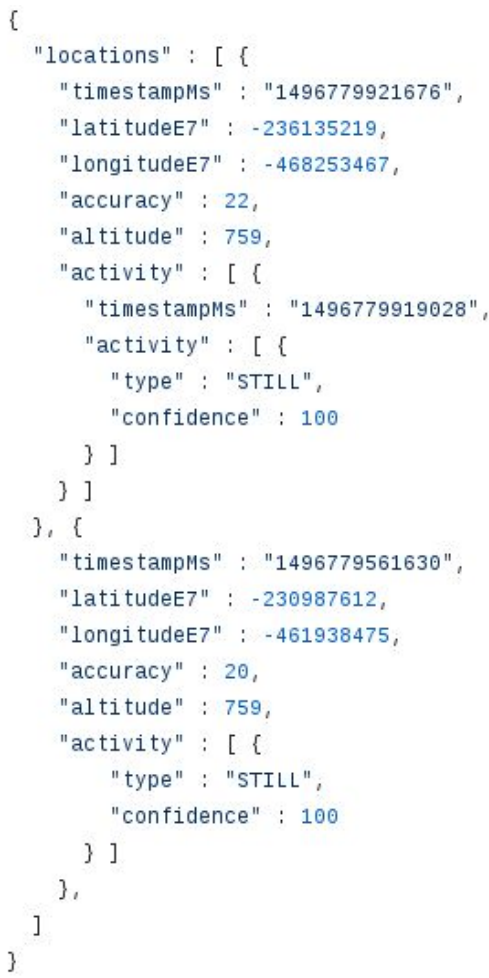

Figura 5. Arquivo hipotético composto por dois pontos no formato dos dados disponibilizados pela plataforma Google Takeout. timestampMs: data e hora da coleta em milissegundos ; latitudeE7: latitude em graus; longitudeE7: Iongitude em graus; accuracy: valor da exatidão em metros da medida de localização.

\subsubsection{Filtro e segmentação temporal}

O histórico de localização enviado pelos pacientes, em geral, deve incluir pontos coletados em um intervalo temporal maior do que o necessário para as análises. Em decorrência disso, um filtro estabelecerá uma janela de tempo baseada na data do diagnóstico da doença. Desta forma, apenas os dados de localização correspondentes à $D$ dias anteriores ao diagnóstico serão armazenados e considerados na análise de dados. No caso da malária, em que os sintomas tendem a 
surgir entre 7 e 10 dias após a picada do mosquito (PHILLIPS et al., 2017), a janela de filtro será $D=90$. A janela de 90 dias foi, posteriormente, segmentada em 3 períodos: sintomático (de 0 a 3 dias antes do diagnóstico), exposição (entre 3 e 30 dias antes do diagnóstico) e pré-exposição (entre 60 e 90 dias antes do diagnóstico) (fig. 6). Esta etapa além de colaborar para redução do tamanho dos arquivos armazenados, será importante para a definição dos locais compartilhados pelos pacientes.

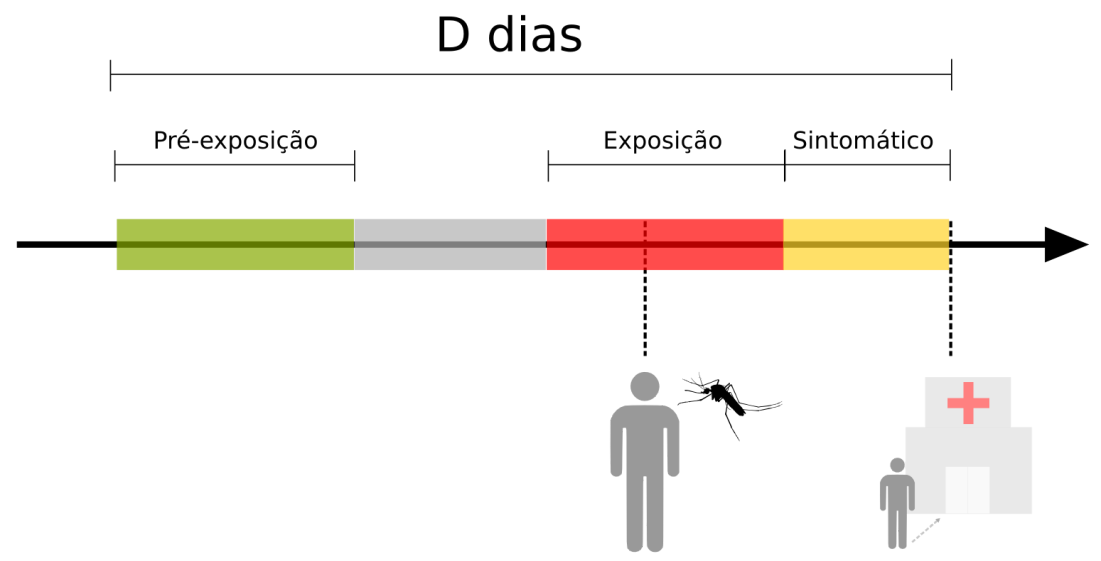

Figura 6. Ilustração da segmentação temporal aplicada aos dados de geolocalização dos pacientes.

\subsubsection{Detecção de potenciais hotspots}

As regiões que necessitam de maior atenção por parte dos órgãos públicos de vigilância são aqui denominadas hotspots. A tarefa de encontrar estas regiões através dos dados de geolocalização de pacientes infectados se baseia na premissa de que, para pacientes que foram infectados num mesmo período de tempo, as regiões geograficamente comuns entre suas trajetórias podem representar locais de infecção compartilhados (fig. 7). Com o objetivo de encontrar os locais de sobreposição 
geográfica entre as trajetórias dos pacientes infectados, foram aplicadas técnicas de estimação da densidade kernel o agrupamento de pontos de parada.

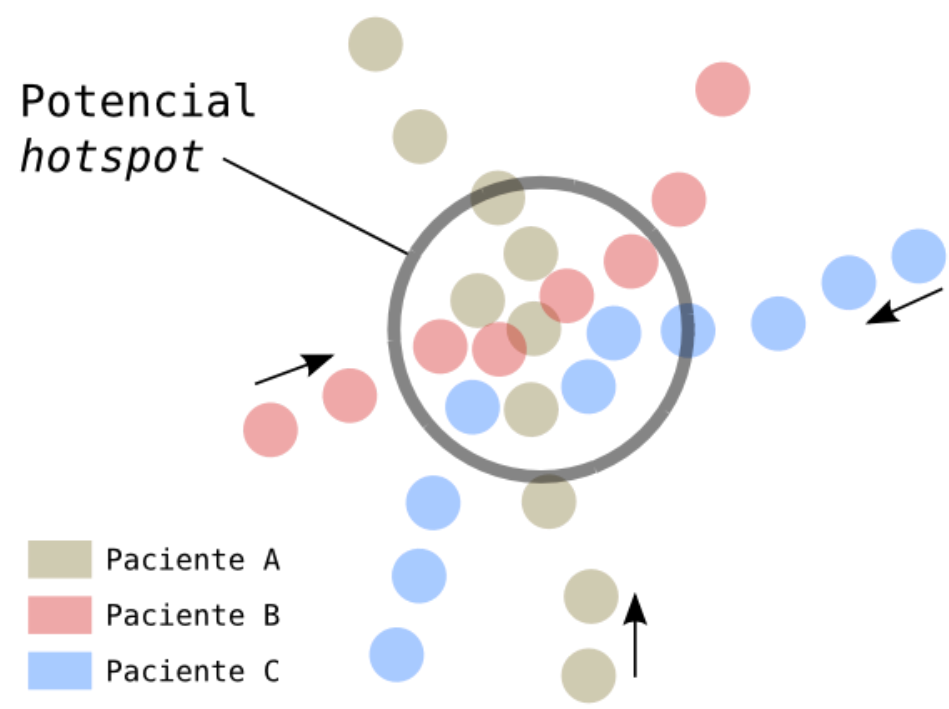

Figura 7. Ilustração da motivação por trás dos algoritmos de sobreposição das trajetórias. Neste exemplo, os três pacientes ( $\mathrm{A}, \mathrm{B}$ e $\mathrm{C}$ ) foram infectados nesta mesma região. Regiões como esta são aqui referidas como hotspots e merecem atenção especial dos órgão de controle epidemiológico.

\subsubsection{Detecção de pontos de parada}

Uma abordagem utilizada em (ZHENG, 2015; ZHENG et al., 2009) para análise de trajetórias é a detecção de pontos de parada. Considere uma trajetória $T$, composta por uma sequência temporal de pontos

$$
T=\left[p_{1} \rightarrow_{\Delta t_{1}}^{\Delta s_{1}} p_{2} \rightarrow_{\Delta t_{2}}^{\Delta s_{2}} \cdots \rightarrow{ }_{\Delta t_{n}}^{\Delta s_{n}} p_{n}\right]
$$

Pontos de parada são definidos como as regiões em que o paciente permaneceu durante um intervalo de tempo em sua trajetória. Para que possamos definir os pontos de parada, duas constantes devem ser consideradas: um limiar de distância $s$ 
e um limiar de tempo $t$. Tecnicamente, um ponto de parada é representado como uma sequência de pontos consecutivos $P=\left[p_{1} \rightarrow_{\Delta t_{1}}^{\Delta s_{1}} p_{2} \rightarrow_{\Delta t_{2}}^{\Delta s_{2}} \quad \ldots \rightarrow \rightarrow_{\Delta t_{n}}^{\Delta s_{n}} p_{n}\right]$ onde $\forall 1>i \geq n, \operatorname{Distância}\left(p_{1}, p_{i}\right) \leq s$ e $\left|p_{n} \cdot T-p_{1} \cdot T\right| \geq t$, onde $p_{n} \cdot T$ representa o tempo em que foi registrado o ponto $p_{n}$. Respeitadas essas condições, o ponto de parada $P$ será composto pelos atributos latitude, longitude, tempo de chegada e tempo de saída (P.lat, P.lon, P.Tarv, P.Tlev), definidos como:

$$
\begin{gathered}
\text { P.lat }=\sum_{1}^{n} p_{n} \cdot \text { lat } /|P|, \\
\text { P.long }=\sum_{1}^{n} p_{n} \cdot \text { long } /|P|, \\
\text { P.Tarv }=p_{1} \cdot T, \\
\text { P.Tlev }=p_{n} . T
\end{gathered}
$$

\subsubsection{Estimação da densidade kernel (KDE)}

Uma forma de análise de sobreposição de coordenadas é a estimação da densidade de pontos. Como um ponto é representado como um par latitude-longitude no modelo esférico da superfície terrestre, utilizaremos a estimação bivariada da densidade kernel (WAND; JONES, 1993). Dada uma amostra aleatória de vetores bivariados x1, x2, ... xn, obtidos de uma função descrita pela função $f$ de densidade, a estimação bivariada da densidade do núcleo é definida como

$$
f_{h}(x)=\frac{1}{n h} \sum_{i=1}^{n} K\left(\frac{x-X_{i}}{h}\right)
$$


onde:

$x=\left(x_{1}, x_{2}\right)^{T}, X_{i}=\left(X_{i 1}, X_{i 2}\right)^{T}, i=1,2, \ldots n$, sendo $n$ o número de pontos;

$h$ é o parâmetro de suavização;

$K$ é a função de kernel, em nosso caso, uma gaussiana.

O resultado da estimação bivariada da densidade kernel é uma função de densidade onde os seus máximos locais representam as regiões com maior concentração de pontos registrados no mapa. Esses locais de alta concentração de pontos podem indicar potenciais hotspots. Esta técnica, porém, é sensível à variação na quantidade de pontos coletados por paciente, podendo revelar hotspots falso positivos em decorrência do excesso de pontos para um mesmo paciente.

\subsubsection{Análise de agrupamento (clustering)}

Técnicas de clustering são muito utilizadas em análise exploratória, por permitir a realização o agrupamento de dados de maneira não supervisionada, se baseando unicamente na similaridade/proximidade entre seus elementos (HASTIE; TIBSHIRANI; FRIEDMAN, 2009). Com base nisso, o algoritmo de agrupamento DBSCAN (ESTER et al., 1996) foi aplicado nos pontos dos de parada entre todos os pacientes. Este algoritmo se baseia na densidade de pontos e depende do parâmetro $\varepsilon$, que representa a distância máxima utilizada para considerar dois pontos como pertencentes a um mesmo grupo (fig. 8). No contexto epidemiológico da transmissão de agentes etiológicos pelo ar, por exemplo, este parâmetro pode ser interpretado como o raio máximo em que um indivíduo infectado pode transmitir o agente 
etiológico para um indivíduo saudável. No caso de doenças em que o vetor é um mosquito, como é o caso da malária, este parâmetro pode ser interpretado como o alcance máximo do vôo do mosquito transmissor.

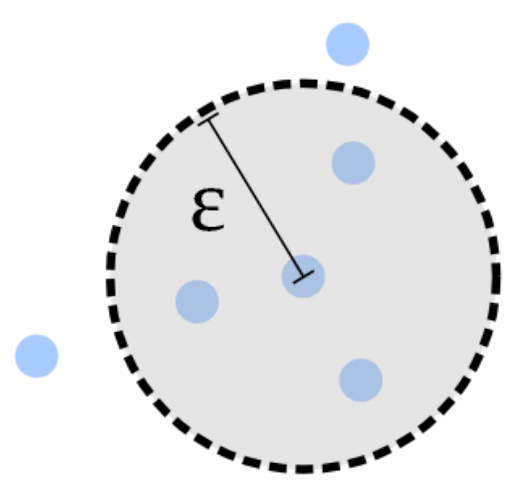

Figura 8. O algoritmo de agrupamento DBSCAN tem $\varepsilon$ como parâmetro principal. Ele representa a distância máxima utilizada para considerar dois pontos como pertencentes a um mesmo cluster.

A análise de agrupamento, por si só, revela apenas os locais com um acúmulo de pontos de parada entre todos os pacientes. Dito isso, é comum encontrarmos clusters formados por pontos de parada de apenas um paciente, por exemplo, em seu local de moradia. Outro artefato desta técnica é a descoberta de clusters em locais onde há um grande fluxo de pessoas, porém um baixo risco de infecção, como, por exemplo, shoppings em áreas urbanas no contexto da picada por mosquitos anofelinos na malária. Assim sendo, para que possamos, portanto, definir quais destes clusters são epidemiologicamente mais informativos, um score de relevância foi atribuído a cada um deles. O cálculo desse score é dado por: 


$$
\text { score }=\left(n_{\text {exp }}-n_{\text {preexp }}\right) \cdot n_{\text {both }}+\frac{1}{\left|L_{\text {sivep }}\right|} \sum_{i=1}^{L_{\text {sivep }}} f\left(w_{i}\right) \exp \left(-\frac{h a v\left(\mathbf{x}_{\mathbf{i}}, \mu\right)^{2}}{2 \sigma^{2}}\right)
$$

onde:

$$
f(w)=\frac{w^{2}}{200^{2}+w^{2}}
$$

$n_{\text {exp }}, n_{\text {preexp }}, n_{\text {both }}$ representam, o número relativo de pacientes passando pelo cluster no período de exposição, pré-exposição e ambos, respectivamente; $L_{\text {sivep }}$ é o conjunto de localidades reportadas no Sistema de Vigilância Epidemiológica para malária (SIVEP) como locais prováveis de infecção; $w_{i}$ representa a quantidade de casos reportados para a localidade $i$ do SIVEP; $x_{i}$ é o vetor no formato [latitude, longitude] para a localização $i$ do SIVEP; $\mu$ é o vetor no formato [latitude, longitude] representando as coordenadas geográficas do centro do cluster; $h a v(x, y)$ é a função que calcula a distância entre dois pontos na superfície terrestre; $\sigma$, dado em quilômetros, é o parâmetro que controla o impacto da distância entre as localidades do SIVEP e o cluster em questão.

Esta equação possui dois termos independentes que são somados, formando o score final de relevância do cluster. O primeiro termo penaliza regiões em que poucos pacientes passaram e onde a diferença entre a quantidade de pacientes passando no período de exposição e período de pré-exposição é pequena. O segundo termo, por sua vez, foi incluído com o objetivo de integrar os dados já disponíveis no SIVEP. Este termo penaliza as regiões que ficam distantes de localidades previamente 
reportadas no sistema de vigilância epidemiológica, dando um valor de relevância maior para aquelas regiões que ficam próximas de localidades com muitos casos reportados.

\section{Resultados e Discussão}

\subsection{Sickness Positioning System (SiPoS)}

O website de coleta dos dados pode ser acessado em https://sipos.fcf.usp.br. Com um fluxo de informações e uma interface intuitiva (fig. 9), o website foi utilizado por pessoas de diferentes idades, de 18 à 50 anos, com o auxílio de nossos colaboradores. 


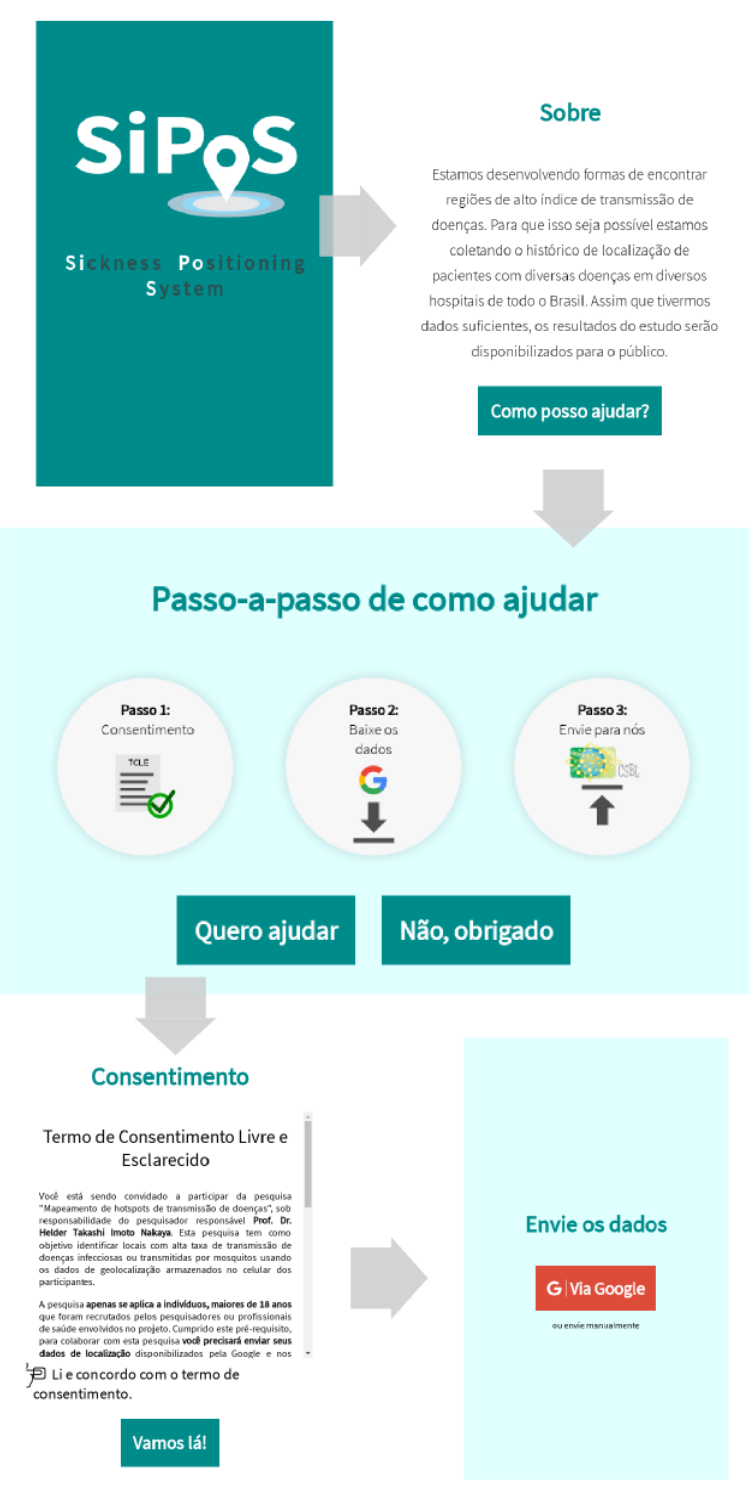

Figura 9. Interface gráfica da aplicação web de coleta dos dados, indicando o passo-a-passo percorrido pelo paciente.

A ferramenta de exploração desenvolvida está hospedada na nuvem e já se encontra disponível no endereço https://sipos.fcf.usp.br/explorer. Os dados de dos pacientes com malária já estão sendo explorados e analisados por uma equipe de epidemiologistas da Fundação de Vigilância em Saúde do estado do Amazonas (fig. 10). 


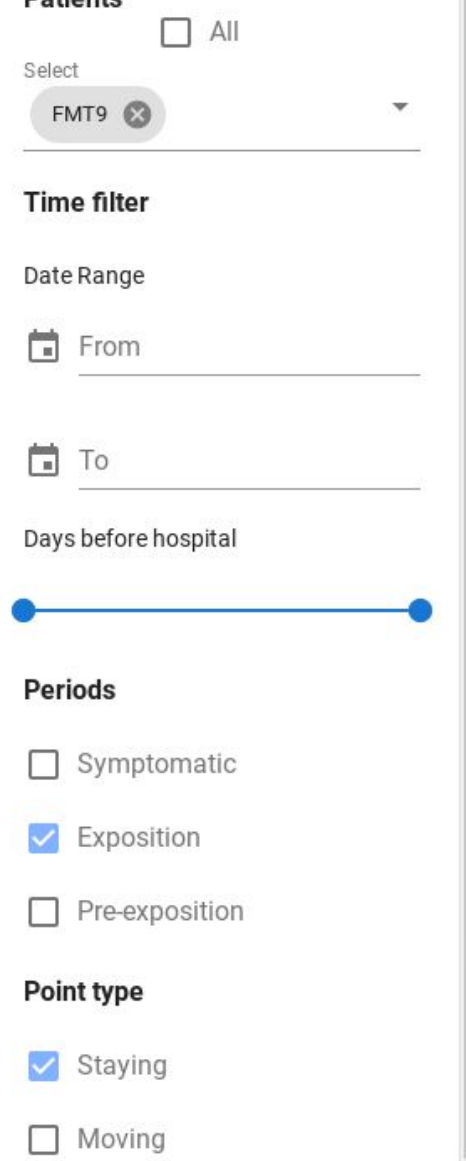

\section{$\equiv$ SiPgS Explorer}

SIVEP locations

Number of cases (>=)

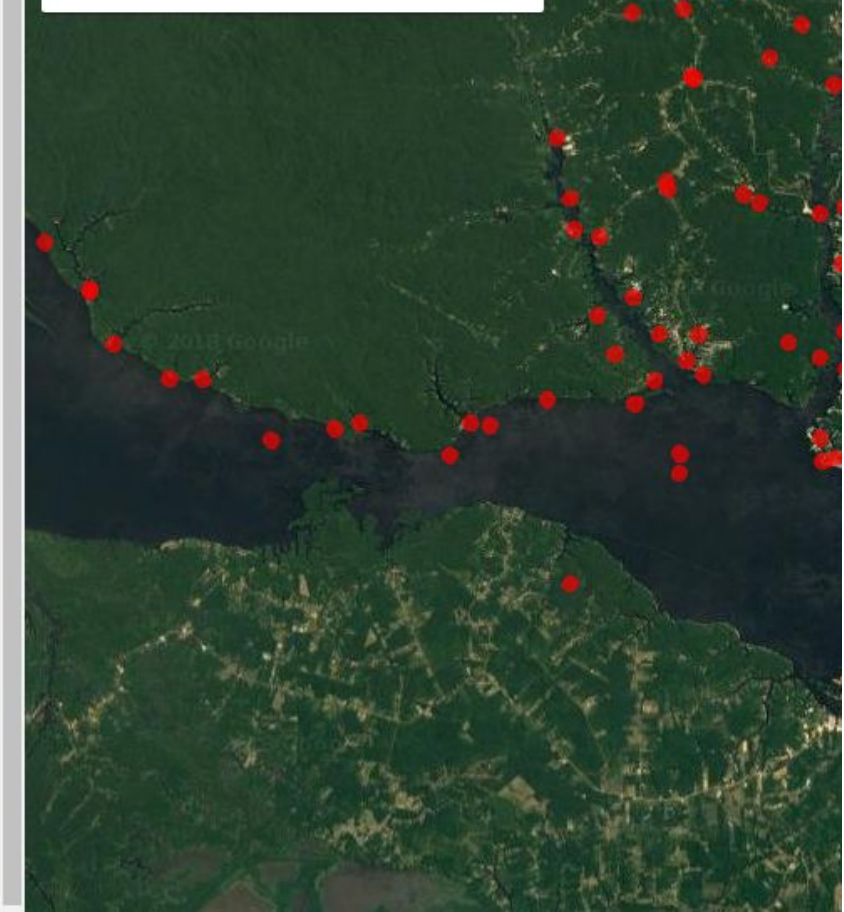

Figura 10. Interface gráfica do SiPoS Explorer para dados de pacientes diagnosticados com malária. No menu lateral, filtros por data, tempo relativo e períodos específicos da doença estão disponíveis auxiliar na análise exploratória dos dados.

\subsection{Malária em Manaus}

Pacientes com sintomas de malária no hospital da Fundação de Medicina Tropical Heitor Vieira Dourado, na cidade de Manaus, AM, foram informados pelos colaboradores a respeito deste estudo, sugerindo-os a colaboração através da doação dos dados. Dos pacientes abordados, 229 positivamente diagnosticados para malária optaram por participar. Diversas motivações estiveram por trás da não adesão dos 
pacientes à pesquisa, sendo a falta e celulares compatíveis a mais frequente entre elas (fig. 11).

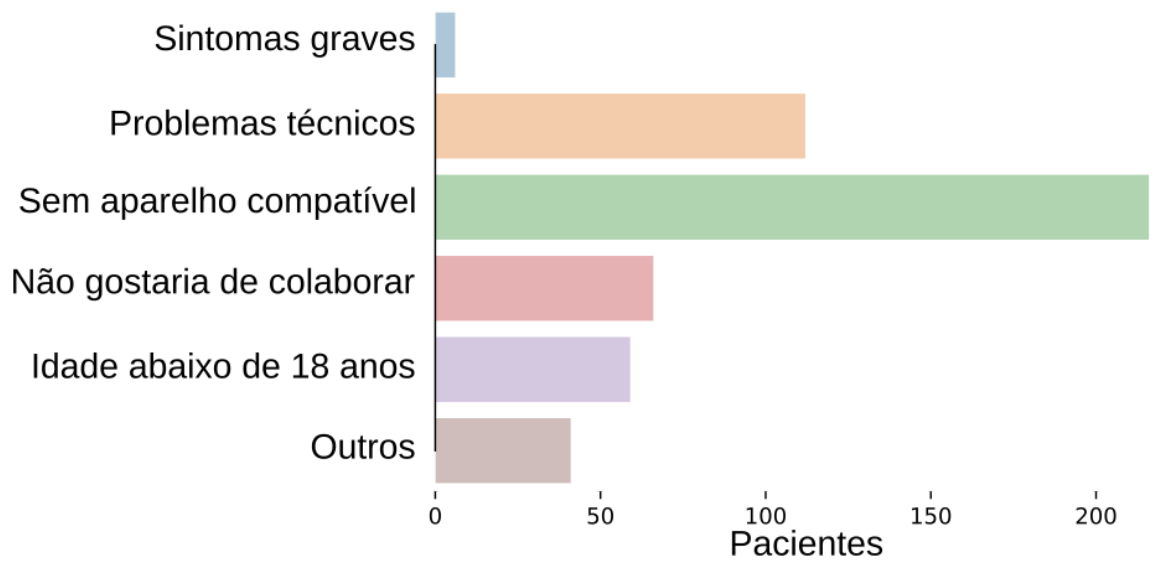

Figura 11. Razões associadas à não participação dos pacientes abordados.

Após a segmentação temporal e o filtro por precisão, dados de 113 pacientes foram utilizados para as futuras análises. O algoritmo de detecção de pontos de parada foi aplicado nos dados com o intuito de reduzir a quantidade de dados armazenados e evidenciar regiões geograficamente importantes para cada paciente (fig. 12). A distribuição da quantidade de pontos de parada por paciente variou entre 1 e 313, com a média de 74.06 e uma mediana de 38 pontos de parada por paciente. A variação na quantidade de pontos de parada entre os pacientes pode ser reflexo direto das diferentes frequências de coleta dos dados, em decorrência de diferentes configurações de hardware (diferentes smartphones) e configurações de software (GPS desabilitado, GPS configurado para modo de baixa precisão, etc). 


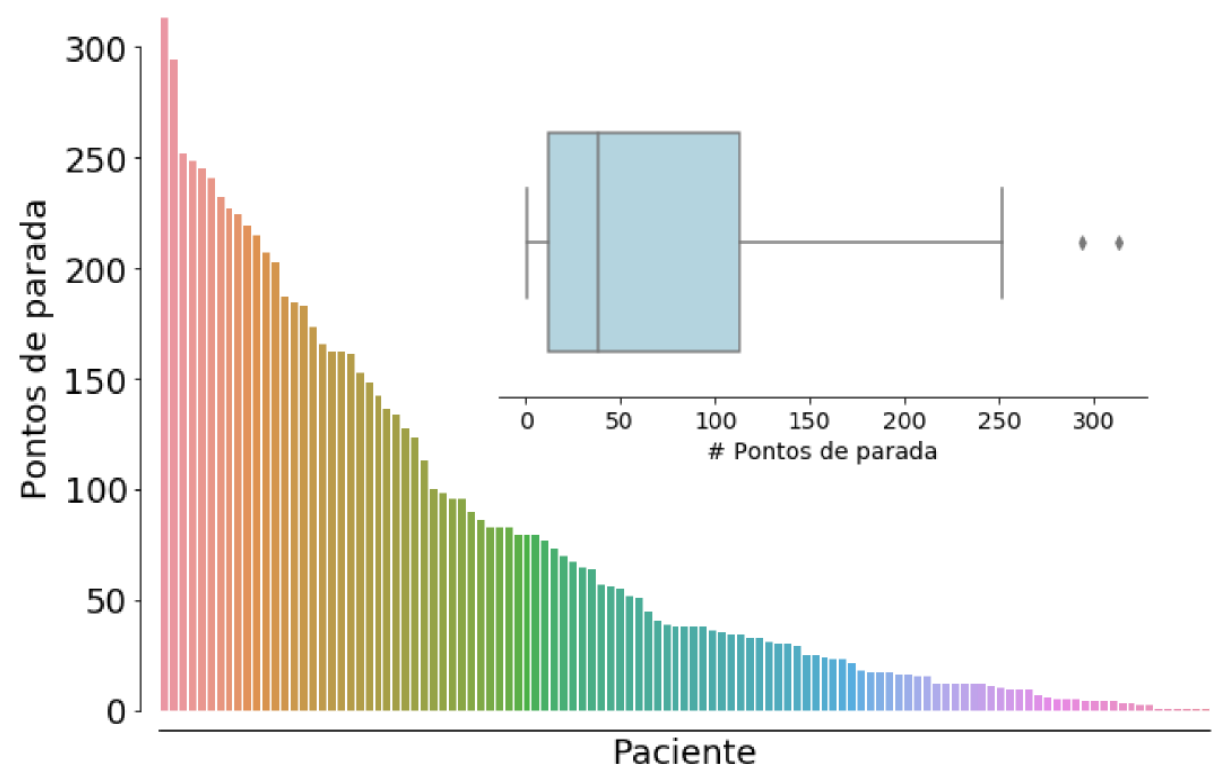

Figura 12. Número de pontos de parada encontrados por paciente e distribuição desses valores. De acordo com a distribuição, a quantidade do número de pontos de parada para cada paciente varia entre 1 e 313, com a média de 74.06 pontos e uma mediana de 38 pontos de parada por paciente.

Estruturas colunares formadas por pontos de parada (vermelhos) na figura 13, indicam a existência de locais importantes para o paciente (locais onde o paciente permanece, consistentemente, durante um determinado período de tempo). Estes locais representam, em geral, o local de moradia e/ou o local trabalho. 


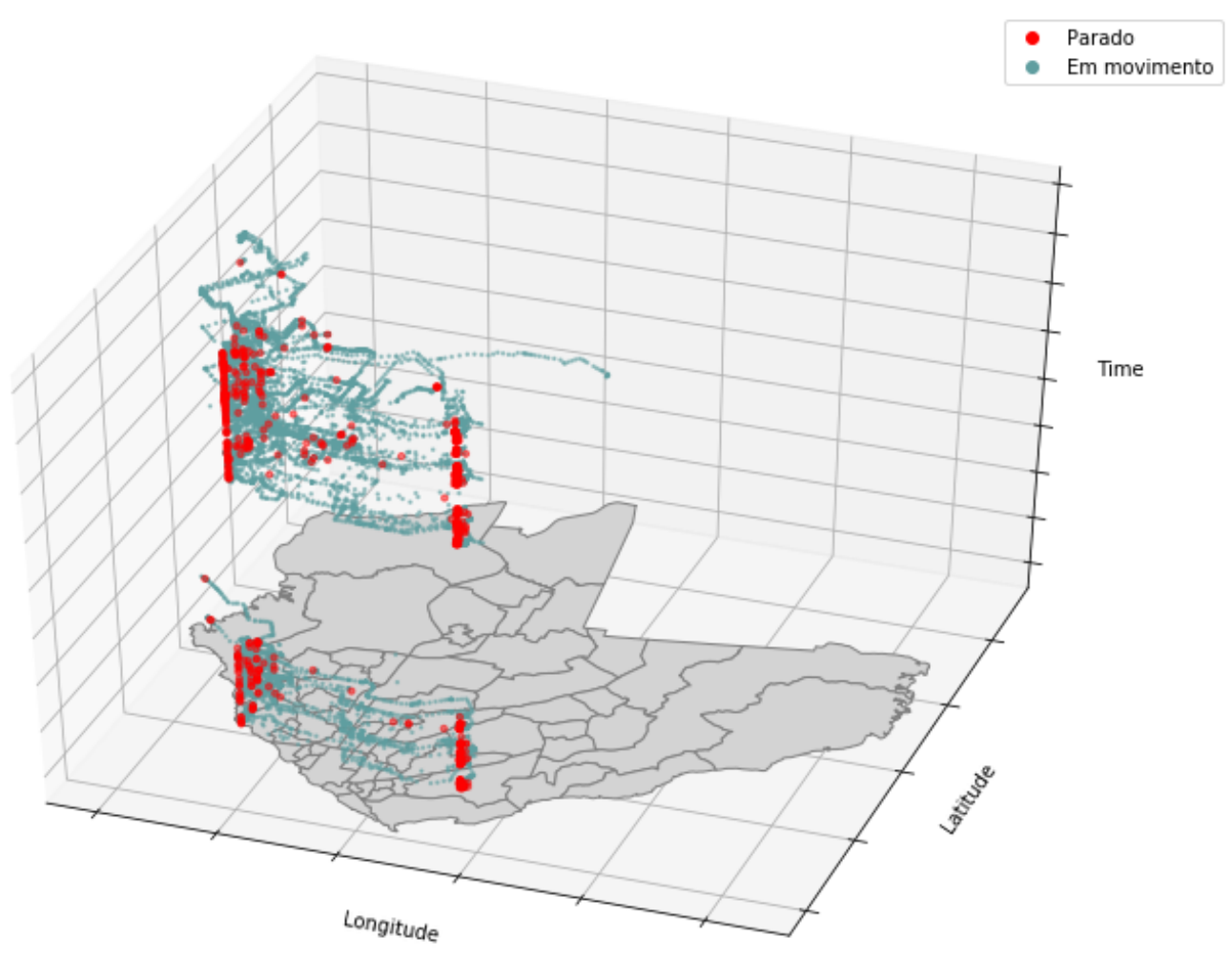

Figura 13. Dados de GPS de um paciente (FMT142) de Manaus, diagnosticado com malária, após a aplicação do algoritmo de detecção de pontos de parada. O eixo vertical representa o tempo em que o ponto foi coletado. Em azul, pontos classificados como "movimento" e, em vermelho, pontos classificados como "parada". O conjunto de pontos mais próximo da base do gráfico representam os pontos do período de exposição ao mosquito e o conjunto superior representa o período de pré-exposição.

Os pontos de parada de todos os pacientes foram submetidos à uma estimação de densidade kernel (fig. 14). É possível notar uma maior concentração de pontos de parada entre a região sul, centro e centro-norte da cidade de Manaus. Como citado na seção de métodos, porém, esta técnica possui a limitação no fato de que seu resultado pode se tornar enviesado na presença de pacientes com uma quantidade discrepante de dados coletados (fig. 12). Apesar desta limitação, ela permite obter uma noção geral das fronteiras geográficas dentre as quais os pontos 
de parada ocorrem.

A

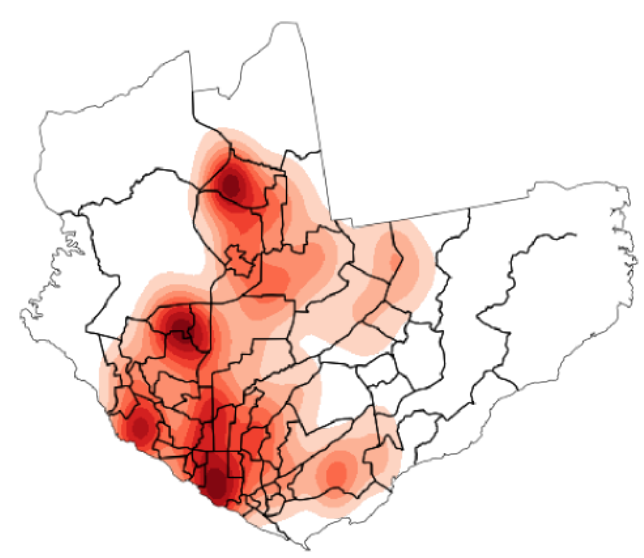

B

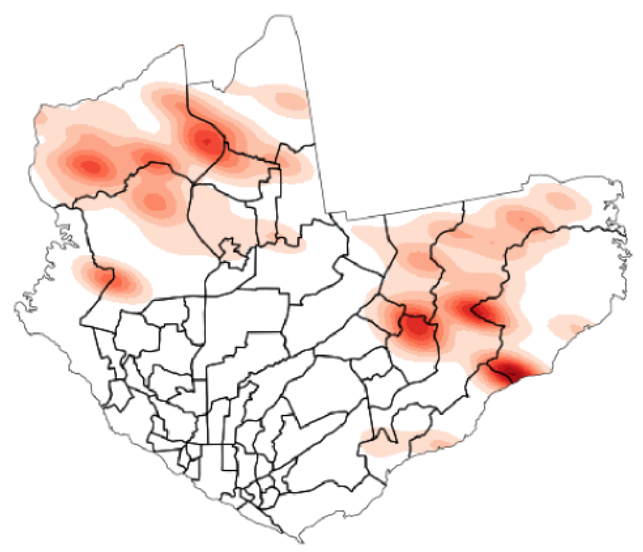

Figura 14. A. Distribuição espacial (KDE) dos pontos de parada de todos os 113 pacientes com malária na cidade de Manaus, AM. B. Distribuição espacial (KDE) dos casos reportados no Sistema de Vigilância Epidemiológica de Malária (SIVEP).

Dadas as limitações mencionadas acima, os pontos de parada de todos os pacientes foram agrupados no intuito de encontrar regiões compartilhadas entre eles. A distribuição da quantidade de pacientes por cluster (fig. 15) revela que a maior parte dos clusters é compartilhada por poucos pacientes. Seguindo o padrão observado na figura 13, a maior parte dos pacientes possui seus pontos de parada concentrados em poucas regiões. Este padrão se alinha com o modelo de mobilidade humana caracterizado por poucos locais com alta frequência de visitação já descrito em GONZÁLEZ; HIDALGO; BARABÁSI, 2008. 


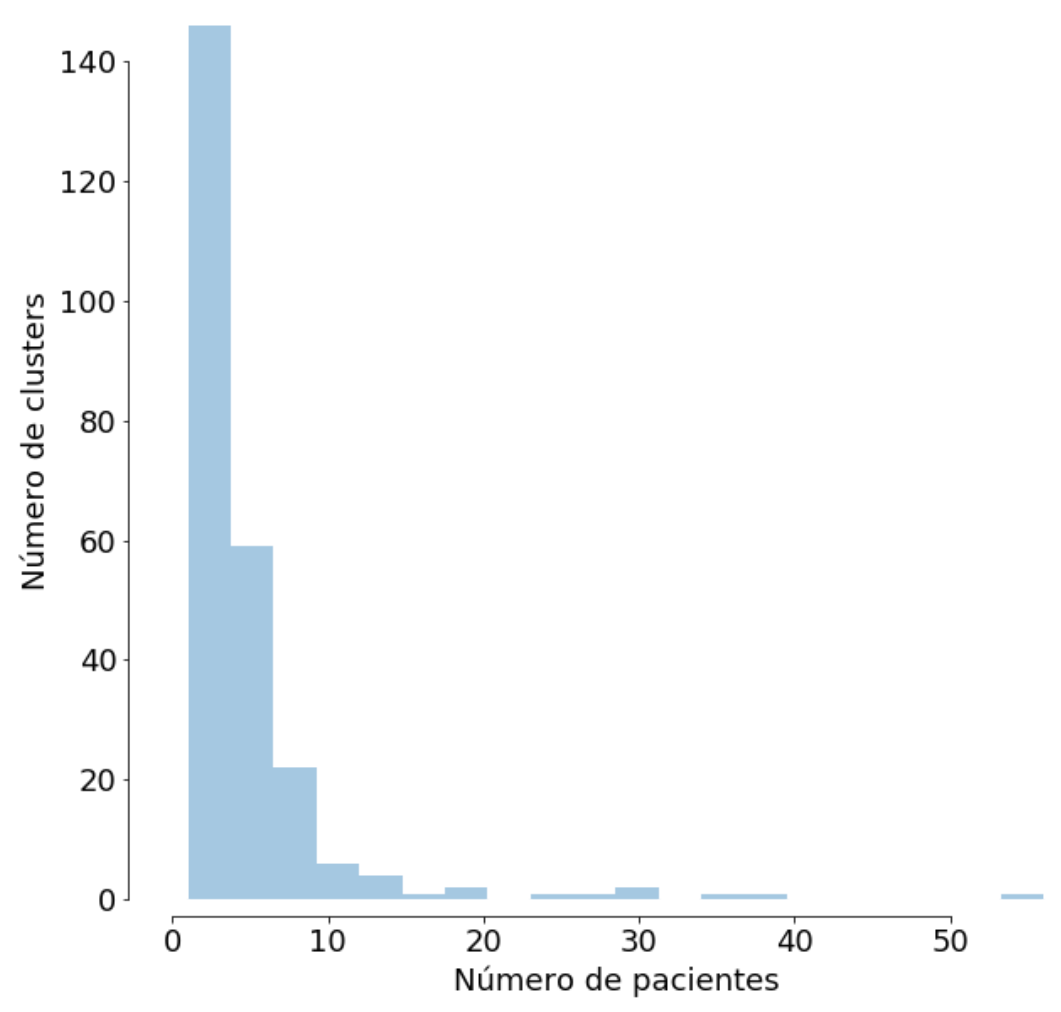

Figura 15. Distribuição da quantidade de pacientes por cluster.

O score de relevância foi calculado para cada um dos clusters (fig. 18). O padrão visual que se torna mais evidente é o aumento no valor da relevância nas regiões mais afastadas do perímetro urbano central. Este padrão reflete a distribuição geográfica dos locais prováveis de infecção com um maior número de casos reportados no SIVEP, que se encontram, majoritariamente, na região periurbana de Manaus (fig. 14 B). 


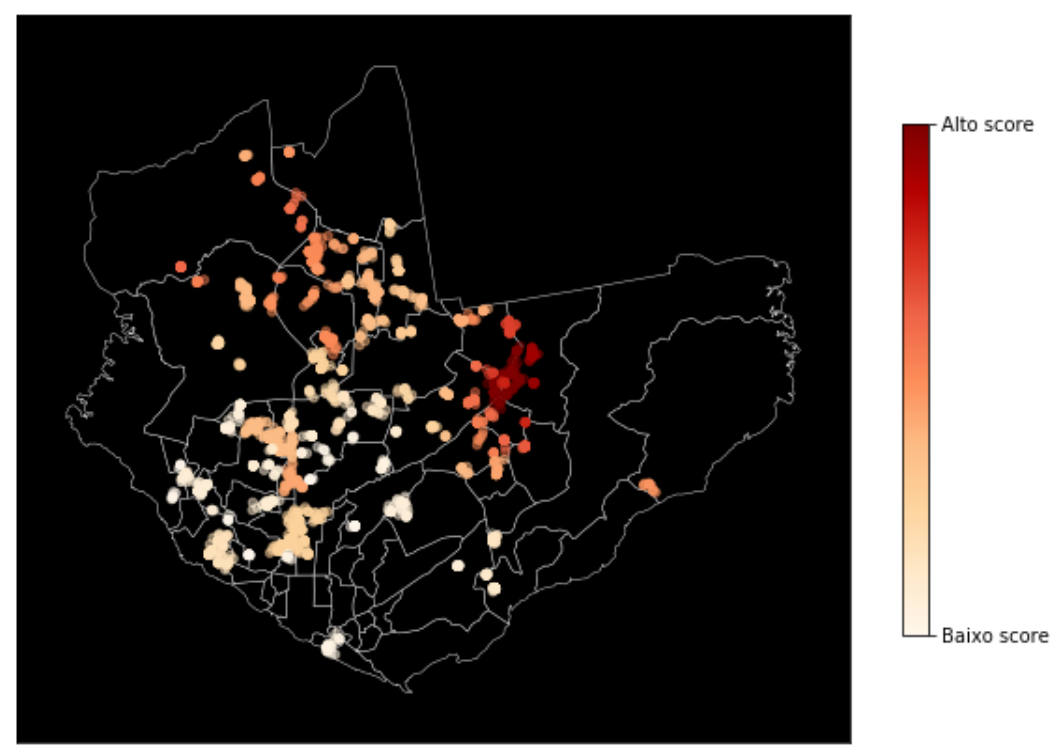

Figura 16. Clusters coloridos pelo nível de relevância dada pelo score proposto.

O impacto de eventuais medidas de controle epidemiológico nas regiões com maior score de relevância, no entanto, deve ser avaliada sob o olhar de especialistas (usuários do SiPos Explorer), que devem considerar variáveis ambientais, sócio-demográficas, além de considerar dados relacionados ao vetor - e.g. quais espécies são representadas na região, qual o comportamento alimentar destas espécies, como os picos de picada se distribuem durante o dia, etc.

\subsection{Aplicações alternativas}

Apesar do sistema aqui desenvolvido ter o foco inicial na epidemiologia da malária, a flexibilidade de seus componentes e dos parâmetros de análise permitem que ele seja aplicado no contexto epidemiológico de outras doenças infecciosas. Considerando isso, dois estudos paralelos foram iniciados na tentativa de utilizar o 
SiPoS como ferramenta de coleta e exploração dos dados de pacientes com sarampo, na FMT-HVD em Manaus, AM e tuberculose, em Salvador, BA.

Ainda que o sarampo e a tuberculose sejam doenças transmitidas pelo ar, a mesma abordagem utilizada para a malária pode ser aplicada em busca dos potenciais hotspots. As únicas adaptações necessárias no pipeline de análise foram a variável utilizada para a definição da relevância de cada cluster (score) e a variável $D$ do filtro temporal. Por serem doenças que não apresentam relação direta com variáveis climáticas, o score de relevância, em ambos os casos, será apenas proporcional à quantidade de pacientes compartilhando o mesmo cluster (fig. 17). 0 encontro destas regiões compartilhadas pela maioria dos pacientes pode guiar o direcionamento das campanhas de vacinação, na tentativa de aumentar seu impacto.
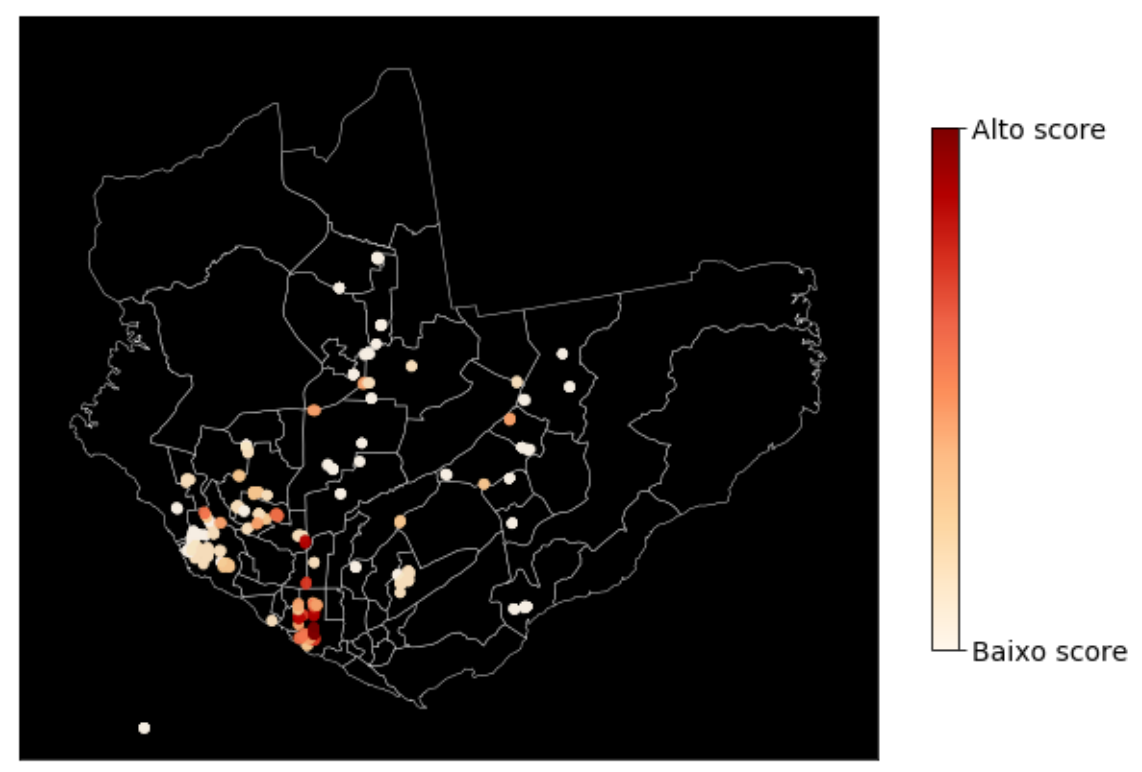

Figura 17. Clusters formados pelos dados de 29 pacientes diagnosticados com sarampo em Manaus, coloridos pela quantidade de pacientes. 


\subsection{Limitações}

Apesar da fonte de obtenção dos dados ser inovadora em estudos epidemiológicos no Brasil, esta abordagem apresenta suas limitações. A primeira limitação é a própria fonte dos dados. Em casos de doenças endêmicas de regiões remotas do país, como a Malária de fronteira nos assentamentos da Amazônia, a parcela de indivíduos que possuem smartphones equipados com GPS pode ser restrita. A segunda limitação está no fato de que as das doenças transmitidas por mosquitos aqui consideradas tem uma parcela notável de casos assintomáticos (BOUSEMA et al., 2014; DUONG et al., 2015; YACTAYO et al., 2016). Esses casos não poderão ser contabilizados neste estudo, visto que a coleta dos dados é realizada no hospital após o aparecimento dos sintomas e o respectivo diagnóstico.

\section{Conclusão}

O sistema SiPoS de coleta, análise e exploração dos dados de geolocalização foi desenvolvido com o intuito de munir os epidemiologistas de dados mais acurados, levando à criação de políticas de controle mais efetivas. Apesar de suas limitações técnicas, o método de análise foi capaz de integrar dados já existentes no Sistema de Vigilância Epidemiológica em malária, e classificar regiões como mais ou menos epidemiologicamente relevantes. A flexibilidade do sistema permitirá que, futuramente, ele seja utilizado no contexto de outras doenças infecciosas como dengue, zika, chikungunya, sarampo, tuberculose, etc. 


\section{Referências Bibliográficas}

ABAY, S. M. Blocking malaria transmission to Anopheles mosquitoes using artemisinin derivatives and primaquine: a systematic review and meta-analysis.

Parasites \& vectors, v. 6, n. 1, p. 278, 24 Sep. 2013.

ALONSO, P. L. et al. The effect of insecticide-treated bed nets on mortality of Gambian children. The Lancet, v. 337, n. 8756, p. 1499-1502, 22 Jun. 1991.

BARROS, F. S. M. DE; HONÓRIO, N. A. Man biting rate seasonal variation of malaria vectors in Roraima, Brazil. Memórias do Instituto Oswaldo Cruz, v. 102, n. 3, p. 299-302, Jun. 2007.

BHATT, S. et al. The global distribution and burden of dengue. Nature, v. 496, n. 7446, p. 504-507, 25 Apr. 2013.

BOUSEMA, T. et al. Asymptomatic malaria infections: detectability, transmissibility and public health relevance. Nature Reviews. Microbiology, v. 12, n. 12, p. 833-840, 20 Oct. 2014.

BUCKEE, C. O. et al. Mobile phones and malaria: modeling human and parasite travel. Travel Medicine and Infectious Disease, v. 11, n. 1, p. 15-22, Feb. 2013.

COMMONS, R. J. et al. The effect of chloroquine dose and primaquine on Plasmodium vivax recurrence: a WorldWide Antimalarial Resistance Network systematic review and individual patient pooled meta-analysis. The Lancet Infectious Diseases, v. 18, n. 9, p. 1025-1034, Sep. 2018.

COSTA, I. M. P.; CALADO, D. C. Incidence of dengue cases (2007-2013) and seasonal distribution of mosquitoes (Diptera: Culicidae) (2012-2013) in Barreiras, Bahia, Brazil. Epidemiologia e servicos de saude : revista do Sistema Unico de Saude do Brasil, v. 25, n. 4, p. 735-744, Dec. 2016.

CUMMINGS, D. A. T. et al. Travelling waves in the occurrence of dengue haemorrhagic fever in Thailand. Nature, v. 427, n. 6972, p. 344-347, 22 Jan. 2004.

DUONG, V. et al. Asymptomatic humans transmit dengue virus to mosquitoes.

Proceedings of the National Academy of Sciences of the United States of America, v. 112, n. 47, p. 14688-14693, 24 Nov. 2015.

ESTER et al. A density-based algorithm for discovering clusters a density-based algorithm for discovering clusters in large spatial databases with noise. 8 Feb. 1996. GOG, J. R. et al. Spatial transmission of 2009 pandemic influenza in the US. PLoS Computational Biology, v. 10, n. 6, p. e1003635, 12 Jun. 2014. 
GONZÁLEZ, M. C.; HIDALGO, C. A.; BARABÁSI, A.-L. Understanding individual human mobility patterns. Nature, v. 453, n. 7196, p. 779-782, 5 Jun. 2008.

GRENFELL, B. T.; BJØRNSTAD, O. N.; KAPPEY, J. Travelling waves and spatial hierarchies in measles epidemics. Nature, v. 414, n. 6865, p. 716-723, 13 Dec. 2001. HASTIE, T.; TIBSHIRANI, R.; FRIEDMAN, J. The Elements of Statistical Learning. New York, NY: Springer New York, 2009.

LE MENACH, A. et al. Travel risk, malaria importation and malaria transmission in Zanzibar. Scientific reports, v. 1, p. 93, 15 Sep. 2011.

MA, C. Integration of GPS and Cellular Networks to Improve Wireless Location Performance. Distribution, 2003.

MORRIS, K. Infrastructure as Code - O'Reilly Media. [s.I.] O’Reilly Media, 2016.

NTONIFOR, N. H.; VEYUFAMBOM, S. Assessing the effective use of mosquito nets in the prevention of malaria in some parts of Mezam division, Northwest Region Cameroon. Malaria Journal, v. 15, n. 1, p. 390, 26 Jul. 2016.

OLIVEIRA-FERREIRA, J. et al. Malaria in Brazil: an overview. Malaria Journal, v. 9, p. 115, 30 Apr. 2010.

ONLINE, R.; MCNAMEE, A. Ethical Issues arising from the Real Time Tracking and Monitoring of People Using GPS-based Location Services. 2005.

PHILLIPS, M. A. et al. Malaria. Nature reviews. Disease primers, v. 3, p. 17050, 3 Aug. 2017.

PROTHERO, R. M. Disease and mobility: a neglected factor in epidemiology. International Journal of Epidemiology, v. 6, n. 3, p. 259-267, Sep. 1977.

SEARLE, K. M. et al. Characterizing and quantifying human movement patterns using GPS data loggers in an area approaching malaria elimination in rural southern Zambia. Royal Society open science, v. 4, n. 5, p. 170046, 3 May 2017.

VAUPEL, T. et al. Wi-Fi positioning: System considerations and device calibration2010 International Conference on Indoor Positioning and Indoor Navigation. Anais... In: 2010 INTERNATIONAL CONFERENCE ON INDOOR POSITIONING AND INDOOR NAVIGATION (IPIN). IEEE, 15 Sep. 2010

VAZQUEZ-PROKOPEC, G. M. et al. Usefulness of commercially available GPS data-loggers for tracking human movement and exposure to dengue virus. International Journal of Health Geographics, v. 8, p. 68, 30 Nov. 2009.

VAZQUEZ-PROKOPEC, G. M. et al. Using GPS technology to quantify human mobility, dynamic contacts and infectious disease dynamics in a resource-poor urban 
environment. Plos One, v. 8, n. 4, p. e58802, 8 Apr. 2013.

WAND, M. P.; JONES, M. C. Comparison of smoothing parameterizations in bivariate kernel density estimation. Journal of the American Statistical Association, v. 88, n. 422, p. 520-528, Jun. 1993.

WESOLOWSKI, A. et al. Quantifying the impact of human mobility on malaria.

Science, v. 338, n. 6104, p. 267-270, 12 Oct. 2012.

WESOLOWSKI, A. et al. Impact of human mobility on the emergence of dengue epidemics in Pakistan. Proceedings of the National Academy of Sciences of the United States of America, v. 112, n. 38, p. 11887-11892, 22 Sep. 2015.

WILLIAMS, N. E. et al. Measures of Human Mobility Using Mobile Phone Records Enhanced with GIS Data. Plos One, v. 10, n. 7, p. e0133630, 20 Jul. 2015.

YACTAYO, S. et al. Epidemiology of chikungunya in the americas. The Journal of Infectious Diseases, v. 214, n. suppl 5, p. S441-S445, 15 Dec. 2016.

ZHENG, Y. et al. Mining interesting locations and travel sequences from GPS trajectoriesProceedings of the 18th international conference on World wide web WWW '09. Anais... In: THE 18TH INTERNATIONAL CONFERENCE. New York, New York, USA: ACM Press, 20 Apr. 2009

ZHENG, Y. Trajectory Data Mining. ACM transactions on intelligent systems and technology, v. 6, n. 3, p. 1-41, 12 May 2015.

\section{Anexos}

\section{Termo de Consentimento}

Você está sendo convidado a participar da pesquisa "Mapeamento de hotspots de transmissão de doenças", sob responsabilidade do pesquisador responsável Prof. Dr. Helder 
Takashi Imoto Nakaya. Esta pesquisa tem como objetivo identificar locais com alta taxa de transmissão de doenças infecciosas ou transmitidas por mosquitos usando os dados de geolocalização armazenados no celular dos participantes.

A pesquisa apenas se aplica a indivíduos, maiores de 18 anos que foram recrutados pelos pesquisadores ou profissionais de saúde envolvidos no projeto. Cumprido este pré-requisito, para colaborar com esta pesquisa você precisará enviar seus dados de localização disponibilizados pela Google e nos informar o código de identificação fornecido pelos pesquisadores ou profissionais de saúde. Os resultados desta pesquisa serão importantes e terão aplicações na área de epidemiologia. O envio desses dados não causa qualquer tipo de prejuízo elou desconforto para os participantes da pesquisa. Nenhuma informação pessoal, incluindo conteúdo de e-mails, fotos, nome ou contatos serão armazenados em nossos servidores.

Durante o processo, você possui o direito de recusar-se a participar da pesquisa, sem prejuízos pessoais. Os dados coletados serão armazenados em um banco de dados seguro e não serão utilizados individualmente para qualquer outra finalidade administrativa ou comercial.

Você poderá entrar em contato com qualquer um dos pesquisadores para tirar dúvidas sobre a pesquisa. Os emails para contato são lucas.cardozo@usp.br (Lucas Cardozo, Laboratório de Biologia de Sistemas Computacional, Departamento de Fisiopatologia e Toxicologia - FCF - USP) e hnakaya@usp.br (Prof. Dr. Helder Nakaya, Laboratório de Biologia de Sistemas Computacional, Departamento de Fisiopatologia e Toxicologia - FCF - USP).

Ao consentir com este termo, você declara que autoriza a sua participação no projeto de pesquisa e que seus dados coletados serão apenas utilizados para análises de cunho científico. Você também declara de que foi informado, de forma clara e detalhada, dos objetivos e dos procedimentos a serem utilizados para a coleta de dados, assim como esclarecido o fato de que sua participação sigilosa não acarretará nenhum prejuízo para a sua situação profissional e pessoal.

\section{Artigos publicados}




\title{
nature
}

COMMUNICATIONS

ARTICLE

DOl: 10.1038/541467-018-03986-3 OPEN

Canonical PI3K $\gamma$ signaling in myeloid cells restricts Trypanosoma cruzi infection and dampens chagasic myocarditis

Maria C. Silva 1,2,12, Marcela Davoli-Ferreira ${ }^{1,2}$, Tiago S. Medina ${ }^{2}$, Renata Sesti-Costa ${ }^{2}$, Grace K. Silva ${ }^{2}$, Carla D. Lopes ${ }^{2}$, Lucas E. Cardozo ${ }^{3}$, Fábio N. Gava ${ }^{4}$, Konstantina Lyroni ${ }^{5}$, Fabrício C. Dias ${ }^{2}$, Amanda F. Frade ${ }^{6,13}$, Monique Baron ${ }^{6}$, Helder I. Nakaya ${ }^{3}{ }^{3}$, Florêncio Figueiredo ${ }^{7}$, José C. Alves-Filho ${ }^{1}$, Fernando Q. Cunha', Christos Tsatsanis $\oplus^{5}$, Christophe Chevillard ${ }^{8}$, Edecio Cunha-Neto $\oplus^{6,9,10}$, Emilio Hirsch $\oplus^{11}$, João S. Silva ${ }^{2} \&$ Thiago M. Cunha?

\begin{abstract}
Chagas disease is caused by infection with the protozoan Trypanosoma cruzi (T. cruzi) and is an important cause of severe inflammatory heart disease. However, the mechanisms driving Chagas disease cardiomyopathy have not been completely elucidated. Here, we show that the canonical PI3K $\gamma$ pathway is upregulated in both human chagasic hearts and hearts of acutely infected mice. PI3Ky-deficient mice and mutant mice carrying catalytically inactive PI3K $\gamma$ are more susceptible to T. cruzi infection. The canonical PI3K $\gamma$ signaling in myeloid cells is essential to restrict $T$. cruzi heart parasitism and ultimately to avoid myocarditis, heart damage, and death of mice. Furthermore, high PIK3CG expression correlates with low parasitism in human Chagas' hearts. In conclusion, these results indicate an essential role of the canonical PI3Ky signaling pathway in the control of $T$. cruzi infection, providing further insight into the molecular mechanisms involved in the pathophysiology of chagasic heart disease.
\end{abstract}




\title{
CEMiTool: a Bioconductor package for performing comprehensive modular co- expression analyses
}

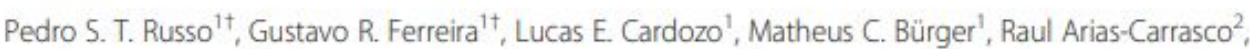
Sandra R. Maruyama ${ }^{3}$, Thiago D. C. Hirata ', Diógenes S. Lima', Fernando M. Passos' ${ }^{1}$, Kiyoshi F. Fukutani ${ }^{3}$, Melissa Lever', João S. Silva ${ }^{3}$, Vinicius Maracaja-Coutinho ${ }^{2}$ and Helder I. Nakaya ${ }^{1 *}$

\begin{abstract}
Background: The analysis of modular gene co-expression networks is a well-established method commonly used for discovering the systems-level functionality of genes. In addition, these studies provide a basis for the discovery of clinically relevant molecular pathways underlying different diseases and conditions.

Results: In this paper, we present a fast and easy-to-use Bioconductor package named CEMiTool that unifies the discovery and the analysis of co-expression modules. Using the same real datasets, we demonstrate that CEMiTool outperforms existing tools, and provides unique results in a user-friendly html report with high quality graphs. Among its features, our tool evaluates whether modules contain genes that are over-represented by specific pathways or that are altered in a specific sample group, as well as it integrates transcriptomic data with interactome information, identifying the potential hubs on each network. We successfully applied CEMiTool to over 1000 transcriptome datasets, and to a new RNA-seq dataset of patients infected with Leishmania, revealing novel insights of the disease's physiopathology.
\end{abstract}

Conclusion: The CEMITool R package provides users with an easy-to-use method to automatically implement gene coexpression network analyses, obtain key information about the discovered gene modules using additional downstream analyses and retrieve publication-ready results via a high-quality interactive report.

Keywords: Co-expression modules, Gene networks, Modular analysis, Leishmaniasis, Transcriptomics 
Perspective

Toxicogenomic and bioinformatics platforms to identify key molecular mechanisms of a curcumin-analogue DM-1 toxicity in melanoma cells

Érica Aparecida de Oliveira ${ }^{a}$, Diogenes Saulo de Lima ${ }^{\mathrm{b}}$, Lucas Esteves Cardozob Garcia Ferreira de Souzac ${ }^{c}$, Nayane de Souza ${ }^{a}$, Debora Kristina Alves-Fernandes ${ }^{a}$, Fernanda Faião-Flores ${ }^{\mathrm{a}}$, José Agustín Pablo Quincoces ${ }^{\mathrm{c}}$, Silvia Berlanga de Moraes Barros ${ }^{\mathrm{a}}$, Helder I. Nakaya ${ }^{\mathrm{b}}$, Gisele Monteiro ${ }^{\mathrm{d}}$, Silvya Stuchi Maria-Engler ${ }^{\mathrm{a}, *}$

${ }^{a}$ Skin Biology Group, Clinical Chemistryand Toxicology Department, Sh hool ofPha rmaceutical Sciences, University of Sao Paub, FCF/USP, Sao Paub, Brazil Computational Syste ms Biology Laboratory, Schoolof Pharmaceutical Sienceș University of Sao Paub, FCF/LSP, Sio Paulo, Braz

Laboratory of Organic Synthesis Anhanguera University of Säo Paulo, LNIAN Sao Paub, Brazil

Bioche mical Pharmaceutical Technology Department, School of Phurmace utical Sciences University of Sao Paulo, FF FJUS, Sao Paub, Brazil

\section{A R T I C L E I N F O}

\section{Article history:}

Received 10 May 2017

Received in revised form 31 July 2017

Accepted 30 August 2017

Av ail able online 4 September 2017

\section{Keywords:}

Curcumin-an alogue

Curcu

Taxicogenomic

Bioinformatic

Melanoma

TOP1

\section{A B S T R A C T}

Melanom a is a highly invasive andmetastatic cancer with high mort ality rates and ch em oresistance Around $50 \%$ of $\mathrm{me}$ an om as are driven by activatingmut ations in BRAF that has led to the developm ent of potent anti-BRAF in hibitors. However resistance to anti-BRAF therapy usually develops within a few $m$ on th $s$ and con sequently the e is a need toi den tify alternativeth e apies that will bypass BRAF inhibitor resist an ce. The curcumin an alogue DM-1 (sodium 4-[5-(4-hydroxy-3-m eth oxy-phenyl)-3-cxo-pent aresist ance. The curcumin an alogue DM-1 (sodium 4-[5-(4-hydroxy-3-m eth oxy-phenyl)-3-cxo-pent a-
1,4-dienyl]-2-m eth oxy-ph enolate) h as substantial anti-tum or activity in m elanom a, but itsm ech ani sm of action remains unclear. Here we use a synth eticleth al genetic screen in Saccharonyces cerevisize to identify 211 genes implicated in sensitivityto DM-1 toxicity. From these 211 genes, $74 \mathrm{~h}$ ad close hum an orth dogues implicated in oxidative ph osph orylation, in sulin sign aling and iron an d RNA metabolism. differential expression during melan am a progression implicated in regulation of tum or progression, cell differentiation, an depith elial-mesen chym al tran sition. Of these TOP1 and ADKwere regulated by DM-1 in treatm ent-n aïve an d vemurafenib-resistant m elanom a cells respectively. These dat a reveal th at the anticancer effect of curcumin analoguesis likely to bem ediat ed viamultiplet argetsand identify sever a genes th at represent can didates for com bin at orial targetingin m d an om a.

(O)2017Elsevier Ltd. All rightsreserved.

\section{Software desenvolvido}


As funções de processamento e análise dos dados de geolocalização desenvolvidas neste presente trabalho foram agrupadas e formam o pacote spots, escrito em Python e disponibilizado em https://github.com/lecardozo/spots. Neste pacote o programador tem acesso à funções para conversão dos dados brutos de geolocalização, disponibilizada no formato JSON, para o formato tabular, permitindo assim uma melhor manipulação dos dados e consequente melhor extração de informações. Além disso, o pacote também expõe a funcionalidade do algoritmo de detecção de pontos de parada e da segmentação temporal, através, respectivamente da classe StayPointDetection e da função time_segment.

\section{rworker}

Grande parcela dos métodos computacionais para análise de dados biológicos possui implementações na linguagem $\mathrm{R}$ de programação, e são disponibilizadas no repositório de pacotes para bioinformática, Bioconductor. Apesar da disponibilidade das técnicas, a necessidade de dominar uma linguagem de programação se torna um fator limitante para a maioria dos pesquisadores das áreas biológicas que desejam utilizar estes métodos. Visando, portanto, facilitar o acesso de pesquisadores leigos em programação aos mais diversos métodos implementados em $\mathrm{R}$, foi criado o pacote rworker.

O pacote rworker, disponível em https://github.com/lecardozo/rworker, utiliza o protocolo de mensagens Celery (http://docs.celeryproject.org/en/latest/internals/protocol.html) para se comunicar com outras aplicações e executar funções em R de maneira assíncrona. Desta forma, 
é possível desenvolver ferramentas web, com interface gráfica amigável para não-programadores, em linguagens como Python e NodeJS, enquanto as análises biológicas são de fato executadas em R.

\section{webCEMiTool}

Como prova de conceito para o pacote rworker descrito acima, a aplicação webCEMiTool foi desenvolvida (https://cemitool.sysbio.tools) (fig. A1). Utilizando o pacote rworker para a execução das análises implementadas em $\mathrm{R}$ pelo pacote CEMiTool, esta aplicação web dá autonomia, através de uma interface gráfica simples e intuitiva para que, pesquisadores não-programadores sejam capazes de realizar suas análises de co-expressão gênica.

\section{OCEMiTool \\ Run About Tutoric}

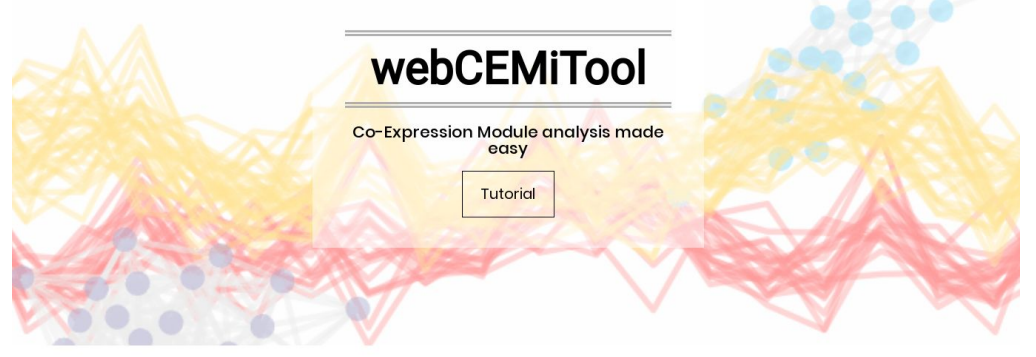

Figura Anexo 1. Captura de tela da ferramenta webCEMiTool, disponibilizada para uso em https://cemitool.sysbio.tools. 


\section{FUNDAÇÃO DE MEDICINA TROPICAL "DOUTOR HEITOR VIEIRA DOURADO"}

\section{PARECER CONSUBSTANCIADO DO CEP}

\section{DADOS DO PROJETO DE PESQUISA}

Título da Pesquisa: AVALIAÇÃO DE UM ALGORITMO DE GEOLOCALIZAÇÃO PARA IDENTIFICAÇÃO DE LOCAL PROVÁVEL DE INFECÇÃO POR MALÁRIA EM PACIENTES DE ÁREA ENDÊMICA DA AMAZÔNIA

Pesquisador: Vanderson de Souza Sampaio

Área Temática:

Versão: 2

CAAE: 68428917.0 .0000 .0005

Instituição Proponente: Diretoria de Ensino e Pesquisa - DENPE

Patrocinador Principal: Financiamento Próprio

DADOS DO PARECER

Número do Parecer: 2.135.257

\section{Apresentação do Projeto:}

Trata-se de um estudo transversal no qual os dados de geolocalização de 500 pacientes com suspeita de malária serão coletados em unidades de saúde de Manaus. Tais dados, são coletados pelo sistema Google Takeout que monitora a localização de usuários com contas Google e uso em equipamentos móveis (tablets e celulares). Um aplicativo web "SiPoS" (www.sipos.fcf.usp.br) foi desenvolvido para simplificar a obtenção destes dados junto ao usuário. O envio dos dados será realizado frente ao aceite do termo de consentimento livre e esclarecido por parte do participante da pesquisa. Uma vez recebidos em um servidor, todos os dados que permitam a identificação do paciente serão codificados para evitar a identificação dos mesmos. Os dados de ponto e linha (informações geográficas) serão analisados por técnicas de análise espacial para identificação de clusters e posteriormente cruzados com o local provável de infecção informado pelo paciente na ficha de notificação do Sistema de Informação Epidemiológica de Malária (SIVEP malária). Serão considerados matchs positivos aqueles onde houver sobreposição entre as duas informações. Os demais serão considerados prováveis erros de local de notificação

\section{Objetivo da Pesquisa:}

OBJETIVO PRIMÁRIO

Utilizar dados provenientes do histórico de localização geográfica dos pacientes com doenças

Endereço: Av. Pedro Teixeira, 25

Bairro: D. Pedro I

UF: AM Município: MANAUS

Telefone: (92)2127-3572

Fax: (92)2127-3572

CEP: $69.040-000$

E-mail: cep@fmt.am.gov.br 


\section{FUNDAÇÃO DE MEDICINA TROPICAL "DOUTOR HEITOR VIEIRA DOURADO"}

Continuação do Parecer: 2.135.257

infecciosas para estimativa de áreas de alto risco de transmissão de malária e estimar a ocorrência de casos de recidiva de malária por Plasmodium vivax na cidade de Manaus OBJETIVOS SECUNDÁRIOS

1. Desenvolver um aplicativo web para coletar dados dos pacientes diagnosticados com malária e implementar algoritmos para análise de sobreposição de dados geográficos dos pacientes.

2. Definir áreas de alta, média e baixa transmissão no município de Manaus - AM;

3. Avaliar o uso do sistema de localização Google Takeout para detecção das áreas de maior circulação dos pacientes com malária por $\mathrm{P}$. vivax.

4. Verificar se o paciente esteve em área de alta, média ou baixa transmissão de malária no período de 60 dias anterior à data dos primeiros sintomas.

5. Comparar as áreas de permanência definidas pelos dados de geolocalização com os dados informados pelo paciente na notificação.

\section{Avaliação dos Riscos e Benefícios:}

Riscos:A pesquisa possui riscos mínimos aos indivíduos participantes. Por se tratar de dados de geolocalização de indivíduos, o processo de coleta, processamento e análise deve ser feito de maneira completamente anônima, para evitar que esses dados sejam, de alguma forma, utilizados contra os participantes da pesquisa. Para evitar esse risco, iremos manter em servidores separados o arquivo JSON (que não possui dados pessoais) e a informação concedida pelos participantes. Apenas um identificador em comum, que não remeterá a nenhum dado pessoal, poderá conectar o arquivo JSON às informações dos participantes. Este identificador ficará sob responsabilidade do pesquisador principal.

Benefícios: A análise dos dados deve revelar regiões de maior índice de transmissão de malária e aumentar a qualidade e precisão das informações relativas aos locais de infecção da doença. Adicionalmente, a identificação de prováveis casos de recorrência podem auxiliar na identificação de falha terapêutica ou ocorrência de resistência. Desta forma, políticas de controle poderão ser mais eficientes.

\section{Comentários e Considerações sobre a Pesquisa:}

A proposta é relevante e dentro do contexto, é plenamente factível, portanto,devidamente instruído, está apto para análise.

Considerações sobre os Termos de apresentação obrigatória:

O protocolo deste estudo traz a documentação: 1 . Folha de rosto da CONEP; 2. Projeto gerado pela

Endereço: Av. Pedro Teixeira, 25

Bairro: D. Pedro I CEP: $69.040-000$

UF: AM Município: MANAUS

Telefone: (92)2127-3572 Fax: (92)2127-3572 E-mail: cep@fmt.am.gov.br 


\section{FUNDAÇÃO DE MEDICINA TROPICAL "DOUTOR HEITOR VIEIRA DOURADO"}

Continuação do Parecer: 2.135.257

Plataforma Brasil (PB); 3. Projeto detalhado; 4. Termo de Consentimento Livre e Esclarecido (TCLE); 5. Cronograma de Execução com início previsto para 05/06/17. 6. Orçamento estimado em $R \$ 3000,00$.

\section{Recomendações:}

PENDÊNCIAS/SOLICITAÇÕES visando atender a Resolução no 446/2012, CNS/MS.

PENDÊNCIA 1: No protocolo apresentado para a devida análise não foi identificado o Termo de Assentimento Livre e Esclarecido (TALE), uma vez que consta no projeto que não existe critérios de exclusão, portanto fica subentendido a participação de pessoas menores de 18 anos na pesquisa. Favor, esclarecer.

ANALISE: Observou-se que o pesquisador atendeu editando o protocolo e incluindo o seguinte trecho "pacientes maiores de 18 anos". Dessa forma, não há necessidade de incluir um TALE.

PENDÊNCIA 2: No protocolo não foi identificado a fonte financiadora da pesquisa, uma vez que na folha de rosto tem a informação "Pesquisas com coordenação e/ou patrocínio

originados fora do Brasil, excetuadas aquelas com patrocínio do Governo Brasileiro"; informar o patrocinador da pesquisa;

ANALISE: Observou-se que o pesquisador atendeu a solicitação, incluindo a fonte de financiamento devidamente corrigida no sistema, assim como a informação sobre patrocínio originado fora do Brasil.Diante disso, PENDÊNCIA ATENDIDA.

PENDÊNCIA 3: O TCLE apresenta palavras de difícil entendimento para o sujeito da pesquisa, como Logout e arquivo JSON. Adequar a linguagem para compreensão do sujeito da pesquisa.

ANÁLISE: Observou-se que o pesquisador atendeu realizando adequação na linguagem do TCLE, conforme recomendação. Onde lia-se: "logout" agora lê-se:"clicando no botão sair". Onde lia-se: "arquivo JSON", agora lê-se: "arquivo com dados pessoais". O texto foi revisado de modo a manter o sentido após os ajustes recomendados.

PENDÊNCIA 4: No TCLE consta a seguinte informação "Se ocorrer qualquer dano ou prejuízo a sua saúde ou integridade, em decorrência deste projeto, você terá direito a

Endereço: Av. Pedro Teixeira, 25

Bairro: D. Pedrol CEP: $69.040-000$

UF: AM Município: MANAUS

Telefone: (92)2127-3572 Fax: (92)2127-3572 E-mail: cep@fmt.am.gov.br 


\section{FUNDAÇÃO DE MEDICINA TROPICAL "DOUTOR HEITOR VIEIRA DOURADO"}

Continuação do Parecer: 2.135.257

indenização". Como será realizado esta indenização e quem a fará se for necessário?

ANÁLISE: Observou-se que o pesquisador atendeu readequando o texto do TCLE.

"Apesar dos riscos desse projeto serem mínimos, se ocorrer qualquer dano ou prejuízo a sua saúde ou integridade, em decorrência deste projeto, você terá direito a ressarcimento e indenização pelo projeto. "

PENDÊNCIA 5: Como o projeto vai utilizar dados secundários, favor providenciar o Termo de Compromisso de Utilização de Dados (TCUD).

ANALISE:Observou-se que o pesquisador atendeu a solicitação, incluindo O TCUD.

PENDÊNCIA 6: Não foi identificado a composição da equipe e seus respectivos curriculum. Favor adequar.

ANALISE: Observou-se que o pesquisador atendeu, incluindo a equipe de trabalho e seus respectivos curriculum.

\section{Conclusões ou Pendências e Lista de Inadequações:}

Diante do exposto acima, sugere-se que o protocolo seja APROVADO, devido o pesquisador ter atendido conforme as solicitações.

S.M.J. É o parecer

\section{Considerações Finais a critério do CEP:}

O presente projeto está APROVADO e os interessados ficam informados de apresentar a este CEP os relatórios parciais e final do estudo, conforme prevê a Resolução CNS nำ466/2012, utilizando o formulário de Roteiro para Relatório Parcial/Final de estudos clínicos Unicêntricos e Multicêntricos, proposto pela CONEP em nossa home page.

Este parecer foi elaborado baseado nos documentos abaixo relacionados:

\begin{tabular}{|l|l|c|c|c|}
\hline \multicolumn{1}{|c|}{ Tipo Documento } & \multicolumn{1}{|c|}{ Arquivo } & Postagem & Autor & Situação \\
\hline $\begin{array}{l}\text { Informações Básicas } \\
\text { do Projeto }\end{array}$ & PB_INFORMAÇÕES_BÁSICAS_DO_P & $05 / 06 / 2017$ & & Aceito \\
\hline
\end{tabular}

Endereço: Av. Pedro Teixeira, 25

Bairro: D. Pedrol CEP: $69.040-000$

UF: AM Município: MANAUS

Telefone: (92)2127-3572 Fax: (92)2127-3572 E-mail: cep@fmt.am.gov.br 


\section{FUNDAÇÃO DE MEDICINA TROPICAL "DOUTOR HEITOR VIEIRA DOURADO"}

Continuação do Parecer: 2.135.257

\begin{tabular}{|c|c|c|c|c|}
\hline Folha de Rosto & folhaDeRosto.pdf & $\begin{array}{c}05 / 06 / 2017 \\
16: 16: 42\end{array}$ & $\begin{array}{l}\text { Vanderson de Souza } \\
\text { Sampaio }\end{array}$ & Aceito \\
\hline Outros & Resposta_Pendencias.pdf & $\begin{array}{c}05 / 06 / 2017 \\
16: 01: 12\end{array}$ & $\begin{array}{l}\text { Vanderson de Souza } \\
\text { Sampaio }\end{array}$ & Aceito \\
\hline Outros & TCUD.pdf & $\begin{array}{c}05 / 06 / 2017 \\
16: 00: 44\end{array}$ & $\begin{array}{l}\text { Vanderson de Souza } \\
\text { Sampaio }\end{array}$ & Aceito \\
\hline $\begin{array}{l}\text { Projeto Detalhado / } \\
\text { Brochura } \\
\text { Investigador }\end{array}$ & Projeto_GPS_Malaria_CEP.docx & $\begin{array}{c}05 / 06 / 2017 \\
15: 58: 59\end{array}$ & $\begin{array}{l}\text { Vanderson de Souza } \\
\text { Sampaio }\end{array}$ & Aceito \\
\hline $\begin{array}{l}\text { TCLE / Termos de } \\
\text { Assentimento / } \\
\text { Justificativa de } \\
\text { Ausência }\end{array}$ & TCLE_Projeto_GTakeout.docx & $\begin{array}{c}05 / 06 / 2017 \\
15: 58: 45\end{array}$ & $\begin{array}{l}\text { Vanderson de Souza } \\
\text { Sampaio }\end{array}$ & Aceito \\
\hline Outros & Declaracao_de_Infraestrutura.pdf & $\begin{array}{c}15 / 05 / 2017 \\
01: 07: 41\end{array}$ & $\begin{array}{l}\text { Vanderson de Souza } \\
\text { Sampaio }\end{array}$ & Aceito \\
\hline $\begin{array}{l}\text { Declaração de } \\
\text { Pesquisadores }\end{array}$ & $\begin{array}{l}\text { Declaracao_de_Compromisso_do_Pesq } \\
\text { uisador.pdf }\end{array}$ & $\begin{array}{c}15 / 05 / 2017 \\
01: 06: 06 \\
\end{array}$ & $\begin{array}{l}\text { Vanderson de Souza } \\
\text { Sampaio }\end{array}$ & Aceito \\
\hline $\begin{array}{l}\text { Declaração de } \\
\text { Instituição e } \\
\text { Infraestrutura } \\
\end{array}$ & $\begin{array}{l}\text { Carta_anuencia_institucional_projeto_G } \\
\text { Takeout.pdf }\end{array}$ & $\begin{array}{c}15 / 05 / 2017 \\
00: 51: 38\end{array}$ & $\begin{array}{l}\text { Vanderson de Souza } \\
\text { Sampaio }\end{array}$ & Aceito \\
\hline
\end{tabular}

\section{Situação do Parecer:}

Aprovado

\section{Necessita Apreciação da CONEP:}

Não

MANAUS, 23 de Junho de 2017

\section{Assinado por:}

Marilaine Martins

(Coordenador)

Endereço: Av. Pedro Teixeira, 25

Bairro: D. Pedro I

UF: AM

Município: MANAUS

Telefone: (92)2127-3572

Fax: (92)2127-3572

E-mail: cep@fmt.am.gov.br 
Fanus - Sistema Administrativo da Pós-Graduação

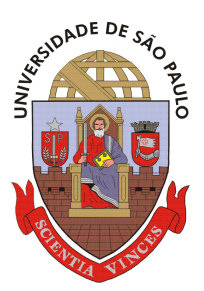

Universidade de São Paulo

Faculdade de Ciências Farmacêuticas

Documento sem validade oficial

FICHA DO ALUNO

\section{2 - 7995726/1 - Lucas Esteves Cardozo}

Email:

lucas.cardozo@usp.br

Data de Nascimento:

29/11/1993

Cédula de Identidade:

RG - 37.098.599-0 - SP

Local de Nascimento:

Estado de São Paulo

Nacionalidade:

Brasileira

Graduação:

Bacharel em Ciências Biológicas - Instituto de Biociências - Universidade de São Paulo - São Paulo - Brasil - 2016

\section{Curso:}

Programa:

Área:

Data de Matrícula:

Início da Contagem de Prazo:

Data Limite para o Depósito:

Orientador:

Proficiência em Línguas:

Data de Aprovação no Exame de Qualificação:

Data do Depósito do Trabalho:

Título do Trabalho:

Data Máxima para Aprovação da

Banca:

Data de Aprovação da Banca:

\section{Data Máxima para Defesa:}

Data da Defesa:

Resultado da Defesa:

Histórico de Ocorrências:

\section{Mestrado}

Farmácia (Fisiopatologia e Toxicologia)

Fisiopatologia

$11 / 07 / 2016$

$11 / 07 / 2016$

$11 / 01 / 2019$

Prof(a). Dr(a). Helder Takashi Imoto Nakaya - 22/02/2017 até o presente. Email: hnakaya@gmail.com

Inglês, Aprovado em 11/07/2016

Aprovado em 29/08/2017 
$10 / 29 / 2018$

Aluno matriculado no Regimento da Pós-Graduação USP (Resolução no 6542 em vigor a partir de 20/04/2013).

Última ocorrência: Matrícula de Acompanhamento em 16/07/2018

Impresso em: 29/10/2018 14:38:21 
Fanus - Sistema Administrativo da Pós-Graduação

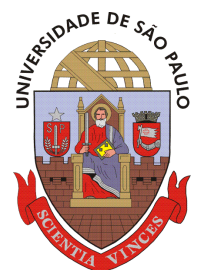

Universidade de São Paulo

\section{Faculdade de Ciências Farmacêuticas}

Documento sem validade oficial

FICHA DO ALUNO

\section{2 - 7995726/1 - Lucas Esteves Cardozo}

\begin{tabular}{|c|c|c|c|c|c|c|c|c|c|}
\hline Sigla & Nome da Disciplina & Início & Término & $\begin{array}{c}\text { Carga } \\
\text { Horária }\end{array}$ & \multicolumn{5}{|c|}{ Cred. Freq. Conc. Exc. Situaçãc } \\
\hline $\begin{array}{l}\text { FBC5757- } \\
7 / 1\end{array}$ & Tópicos em Fisiopatologia e Toxicologia II & $02 / 08 / 2016$ & $14 / 11 / 2016$ & 15 & 1 & 100 & $A$ & $\mathrm{~N}$ & Concluída \\
\hline $\begin{array}{l}\text { BMI5863- } \\
\quad 8 / 2\end{array}$ & $\begin{array}{l}\text { Seminário Didático-Cientifico em Imunologia II (Instituto de Ciências Biomédicas - Universidade de São } \\
\text { Paulo) }\end{array}$ & $18 / 08 / 2016$ & $30 / 11 / 2016$ & 60 & 4 & 90 & $A$ & $\mathrm{~N}$ & Concluída \\
\hline $\begin{array}{l}\text { PCS5031- } \\
1 / 2\end{array}$ & Introdução à Ciência dos Dados (Escola Politécnica - Universidade de São Paulo) & $12 / 09 / 2016$ & $04 / 12 / 2016$ & 120 & 8 & 100 & A & $\mathrm{N}$ & Concluída \\
\hline $\begin{array}{l}\text { FBC5707- } \\
\quad 6 / 1\end{array}$ & Biologia de Sistemas para Ciências da Vida & $26 / 10 / 2016$ & 08/12/2016 & 60 & 4 & 100 & $A$ & $\mathrm{~N}$ & Concluída \\
\hline $\begin{array}{l}\text { PCS5024- } \\
1 / 3\end{array}$ & Aprendizado Estatístico (Escola Politécnica - Universidade de São Paulo) & $20 / 02 / 2017$ & $14 / 05 / 2017$ & 120 & 8 & 100 & B & $\mathrm{N}$ & Concluída \\
\hline $\begin{array}{l}\text { FBC5793- } \\
\quad 13 / 1\end{array}$ & Tópicos em Fisiopatologia e Toxicologia I & $07 / 03 / 2017$ & $19 / 06 / 2017$ & 15 & 0 & - & - & $\mathrm{N}$ & $\begin{array}{l}\text { Matrícula } \\
\text { cancelada }\end{array}$ \\
\hline $\begin{array}{l}\text { FBC5793- } \\
\quad 14 / 1\end{array}$ & Tópicos em Fisiopatologia e Toxicologia I & 05/03/2018 & 19/06/2018 & 15 & 1 & 100 & A & $\mathrm{N}$ & Concluída \\
\hline
\end{tabular}

\begin{tabular}{|l|cc|c|}
\hline & \multicolumn{2}{|c|}{ Créditos mínimos exigidos } & Créditos obtidos \\
\hline & Para exame de qualificação & Para depósito da dissertação & \\
\hline Disciplinas: & 0 & 25 & 26 \\
\hline Estágios: & & & 26 \\
\hline Total: & 0 & 25 & 26 \\
\hline
\end{tabular}

Créditos Atribuídos à Dissertação: 71

A - Excelente, com direito a crédito; B - Bom, com direito a crédito; C - Regular, com direito a crédito; R - Reprovado; T - Transferência.
Um(1) crédito equivale a 15 horas de atividade programada.

Última ocorrência: Matrícula de Acompanhamento em 16/07/2018

Impresso em: 29/10/2018 14:38:22 


\section{且CNPq

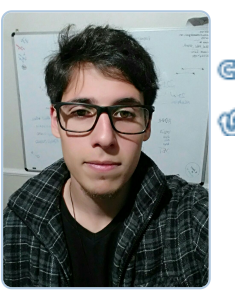

\section{Lucas Esteves Cardozo}

(5) Endereço para acessar este CV:http://lattes.cnpq.br/2294222587464018

(Última atualização do currículo em 27/10/2018

Resumo informado pelo autor

Mestrado em andamento no Laboratório de Biologia de Sistemas Computacional (Faculdade de Ciências Farmacêuticas - USP), pelo programa de pós-graduação em Fisiopatologia e Toxicologia. Graduado em 2016 em Ciências Biológicas pela Universidade de São Paulo. Em 2014 iniciou estudos no Laboratório de Biologia de Sistemas Computacional, onde adquiriu e aperfeiçoou seus conhecimentos na área de biologia de sistemas e análise de dados de genômica e transcriptômica. Atualmente, também participa de projetos envolvendo desenvolvimento de aplicativos e ferramentas para bioinformática. Nas ciências biológicas, possui interesse pelas áreas de biologia de sistemas e bioinformática. Nas ciências da computação, possui interesse em técnicas de aprendizado de máquina, teoria dos grafos, visualização de dados e engenharia de software.

(Texto informado pelo autor)

Nome civil

Nome Lucas Esteves Cardozo

\section{Dados pessoais}

Filiação Antonio Neres Cardozo e Sonia Regina Toia Esteves Cardozo

Nascimento 29/11/1993 - São Paulo/SP - Brasil

Carteira de 370987990 SSP - SP - 09/03/2011 Identidade

CPF $\quad 419.313 .468-79$

\section{Formação acadêmica/titulação}

2016 Mestrado em Fisiopatologia e Toxicologia

Farmacêuticas - USP, FCF - USP, Brasi

位

acientes

Orientador: Helder Takashi Imoto Nakaya

Bolsista do(a): Conselho Nacional de Desenvolvimento Científico e Tecnológico 
2012 - 2016 Graduação em Ciências Biológicas.

Universidade de São Paulo, USP, Sao Paulo, Brasil

Título: Biologia de Sistemas da Vacina de Cercária Atenuada de Schistosoma mansoni

Orientador: Helder Takashi Imoto Nakaya

Bolsista do(a): Conselho Nacional de Desenvolvimento Científico e Tecnológico

Projetos

Projeto de

extensão

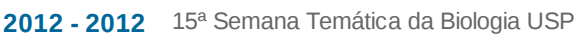

Descrição: Descrição: A Semana Temática da Biologia é um projeto de extensão universitária idealizado em 1997, pelo Centro Acadêmico do Instituto de Biociências da USP, com o objetivo de suprir lacunas na grade do curso, promover interação entre alunos e professores e ainda mostrar o vasto campo de atuação do biólogo. Durante a Semana, ocorrem palestras, cursos, minicursos, oficinas e um debate, além de concursos e exposições. Contamos, na 15a edição, com a Exposição Acadêmica, um espaço aberto para a divulgação da produção científica dos participantes do evento, com o concurso de fotos e com o concurso de ilustração Biológica. Nesse ano, também incentivamos a discussão sobre temas diversos, compondo nossa grade com uma Mesa Redonda.

Alunos envolvidos: Graduação (20):

Integrantes: Lucas Esteves Cardozo; Gisele Akemi Oda (Responsável)

\section{Producão}

Produção bibliográfica

Artigos completos publicados em periódicos

1. If doi> SILVA, MARIA C.; DAVOLI-FERREIRA, MARCELA; MEDINA, TIAGO S.; SESTI-COSTA, RENATA; SILVA, GRACE K.; LOPES, CARLA D.; CARDOZO, LUCAS E.; GAVA, FÁBIO N.; LYRONI, KONSTANTINA; DIAS, FABRÍCIO C.; FRADE, AMANDA F.; BARON, MONIQUE; NAKAYA, HELDER I.; FIGUEIREDO, FLORENCIO; ALVES-FILHO, JOSE C.; CUNHA, FERNANDO Q.; TSATSANIS, CHRISTOS; CHEVILLARD, CHRISTOPHE; CUNHA-NETO, EDECIO; HIRSCH, EMILIO; SILVA, JOÃO S. CUNHA, THIAGO M

Canosictic myocarditis. Nature Communications. JCR, v.9, p.1513 - , 2018.

2. doi> RUSSO, PEDRO S. T.; FERREIRA, GUSTAVO R.; CARDOZO, LUCAS E.; BÜRGER, MATHEUS C.; ARIAS-CARRASCO, RAUL; MARUYAMA, SANDRA R.; HIRATA, THIAGO D. C.; LIMA, DIÓGENES S PASSOS, FERNANDO M.; FUKUTANI, KIYOSHI F.; COUTINHO, VINICIUS; NAKAYA, HELDER I.

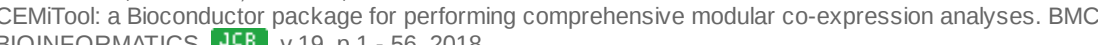

3. doi> DE OLIVEIRA, ÉRICA APARECIDA; DE LIMA, DIOGENES SAULO; CARDOZO, LUCAS

ESTEVES; DE SOUZA, GARCIA FERREIRA; DE SOUZA, NAYANE; ALVES-FERNANDES, DEBORA KRISTINA; FAIÃO-FLORES, FERNANDA; PABLO QUINCOCES, JOSÉ AGUSTIIN; DE MORAES BARROS, SILVIA BERLANGA; NAKAYA, HELDER I.; MONTEIRO, GISELE; MARIA-ENGLER, SILVYA STUCHI

Toxicogenomic and bioinformatics platforms to identify key molecular mechanisms of a curcumin-analogue DM-1 toxicity in melanoma cells. PHARMACOLOGICAL RESEARCH. JCR, p.178 - 187, 2017.

Apresentação de trabalho e palestra

1. ICARDOZO, L. E.

Mapeando hotspots de doenças usando GPS de celular de pacientes, 2018. (Simpósio,Apresentação de Trabalho) 
2. A CARDOZO, L. E.

Mapping Hotspots for Mosquito-Human Malaria Transmission, 2017. (Conferência ou palestra,Apresentação de Trabalho)

3. RUSSO, P. S. T.; FERREIRA, G. R.; MEDINA, C. A. P.; BÜRGER, M. C.; CARDOZO, L. E.; FONSECA, L. S.; HIRATA, T. D. C.; HERMOSILLA, G. S.; COUTINHO, V. M.; NAKAYA, H. I. CEMiTool: Co-expression Modules Identification Tool, 2016. (Congresso,Apresentação de Trabalho)

4. OLIVEIRA, E. A.; SOUZA, G. F.; LIMA, D. S.; CARDOZO, L. E.; FLORES, F. F.; SUAREZ, J. A. P. Q. NAKAYA, H. I.; MONTEIRO, G.; MARIA-ENGLER, S. S.

Integrative toxicogenomic and system biology platforms to target melanoma genes by DM-1, 2016

(Congresso,Apresentação de Trabalho)

5. BÜRGER, M. C.; CARDOZO, L. E.; HIRATA, T. D. C.; NAKAYA, H. T. I.

Long Noncoding RNAs in Patients with Dengue: Insights into Gene Regulation, 2016.

6. HIRATA, T. D. C.; NAKAYA, H. I.; BÜRGER, M. C.; LIMA, D. S.; RUSSO, P. S. T.; FERREIRA, G. R.; CARDOZO, L. E.; BRAGA, A. A.; SALDARRIAGA, M. E. G.; HIRATA, R. D. C.; HIRATA, M. H.

Systems Biology Approach to Study Metabolic Syndrome, 2016. (Congresso,Apresentação de Trabalho)

Produção técnica

Programa de computador sem registro

1. CARDOZO, LUCAS ESTEVES bioboard, 2018 2. CARDOZO, LUCAS ESTEVES

Página gerada pelo sistema Currículo Lattes em 29/10/2018 às 13:42:52. 